\title{
الطرائق والأساليب المنهجية في الدراسات الإعلامية
}

أ.م.د رشيد حسين الشمري

كلية الإعلام - جامعة بغداد

\section{المقدمة}

لقــ كثـرت الكتابـات والنقاشـات التي تطرقـت الى تاصيل مناهج البحث وتفسـيرها وتحديد

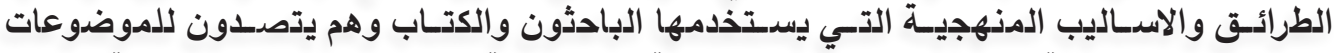

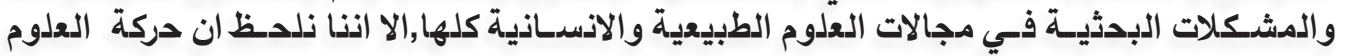

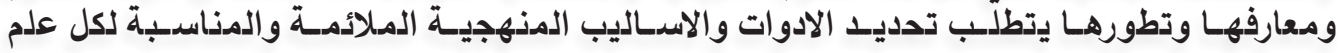

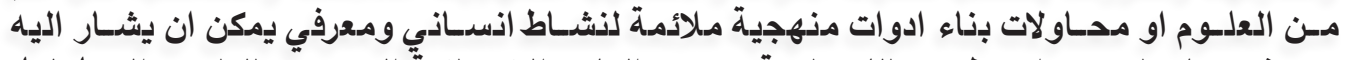

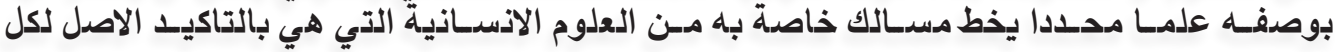

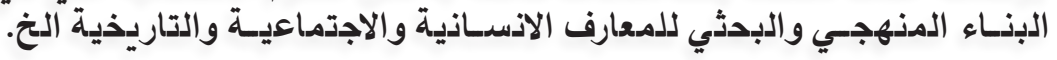

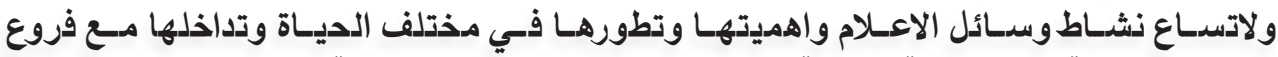

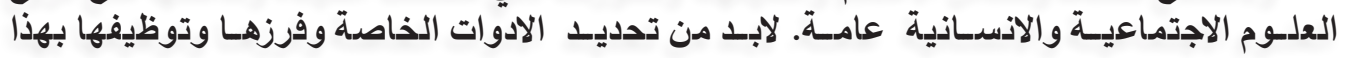

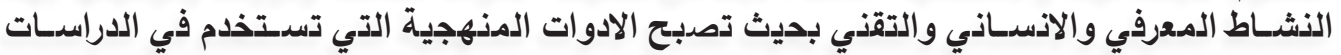

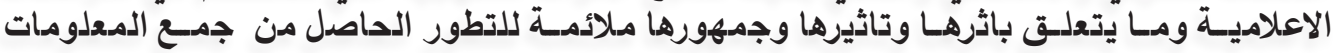

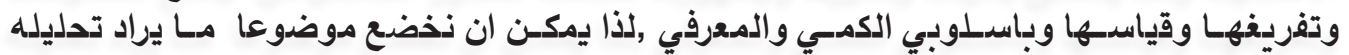

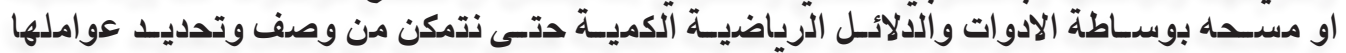

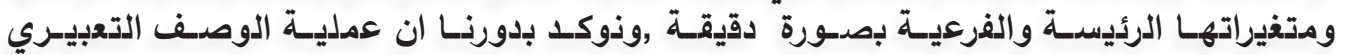

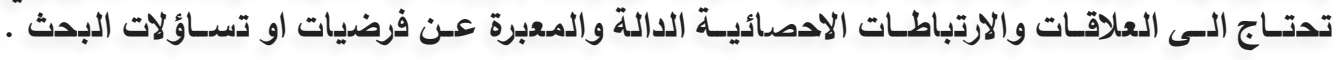
وما سدنده في بحثنا هذا هي محاوات علمية تسدى لايجاد طرائق المناهج العلدية الخاصة

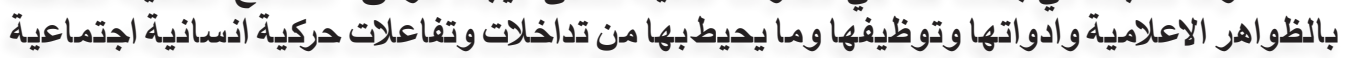

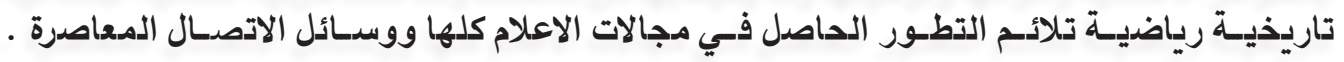

E-aklla_rasheed@yahoo.com

\begin{tabular}{c|c} 
& العلة الباحث الإعلامي
\end{tabular}




\title{
Modalities and Methodological Techniques in Media Studies
}

\author{
Ass.Prof: Rasheed Hussain Al-shimari \\ University of Baghdad / College of Media \\ E-aklla_rasheed@yahoo.com
}

\section{Introduction:}

There have been many writings and discussions that dealt with the details and interpretation of the research methods and the identification of the methods and methodological methods used by researchers and writers as they deal with research topics and problems in all fields of natural and human sciences. But we noticed that the movement of science and its knowledge and development requires the identification of suitable tools and methodological methods appropriate for each type of science. In other words, attempts should be established to build appropriate methodological tools for human and cognitive activity that can be referred to as a specific science that sets out certain paths of the human sciences which is certainly the origin of all the systematic and research construction of human, social and historical knowledge, etc. Due to the expansion of the media' activity and its importance and development in different life and overlapping with the branches of social and human sciences in general, it is necessary to identify and sort special tools employing them with this human and technical activity. Thus, that the methodological tools used in media studies with their impact and effect and audience are appropriate for the development of information gathering and measuring quantitatively and qualitatively. So we can subject a topic to be analyzed or surveyed by means of quantitative mathematical tools and indices so that we can describe and determine their factors and its main and subsidiary variables accurately. By turn, we confirm that the process of depicted description needs to set of relations and statistical links that should be available to reflect the hypotheses or queries of the research. What we will find in this research are scientific attempts to find scientific methods and tools aiming to establish special scientific approaches media phenomena for and its surrounding interferences and dynamic interact.

Key word: Method, Modalities .Mwthodological. Technianes

\begin{tabular}{c|c} 
& العجلة الباحث الإعلامي \\
\hline$\Lambda$ & إعدد ( اء )
\end{tabular}




\section{اولا : التعريف بالمنهاجية العلمية}

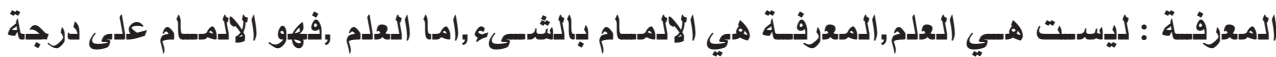

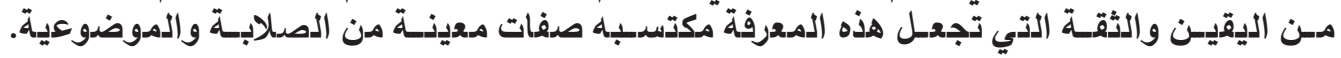

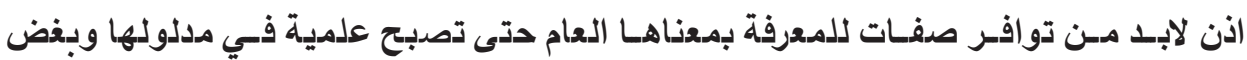

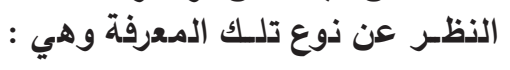

\section{ا ـ يجب ان يكون موضدوع المعرفة واضحاً وقابلاً للتحديد . .}

r. لـها منهاجية ذاتية تذبع من طبيعة الظاهرة وتعبر عن جوهر تلك لظاهرة.

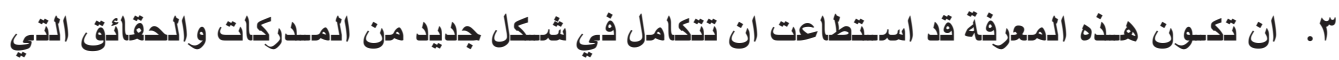
بمجموعها تكـون تلك الظاهرة.

وبهذا التحديد للصففات يجب ان تتحدد المعرفة وان تدور حول موضدوع واضح قابل للتحديد ويرتبط

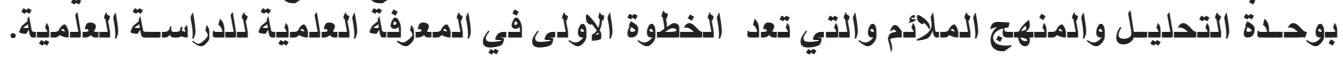

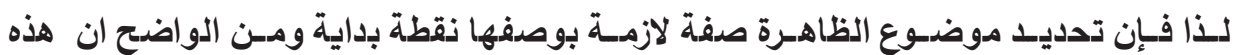

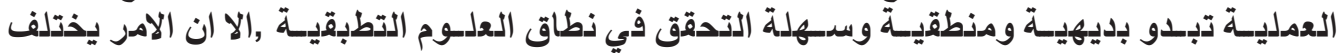

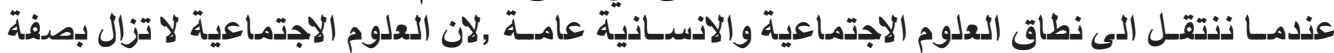

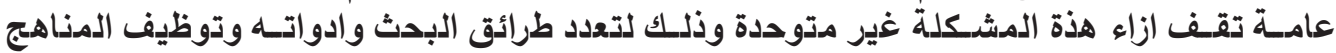

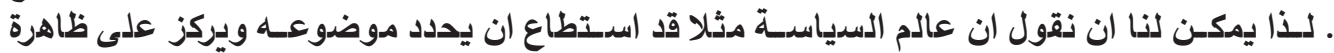

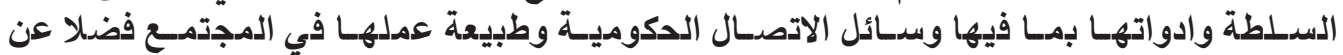
اتجاهـات الراي الـعام وادواته

ولابد لنا ان نطرح السؤال : ما العمليات التي تسدمح بتدديد موضدوع المعرفة؟ والتحديـد يعذـي عملية التميز للظاهـرة والفرز فضلا عن التصدور العقلي والتجريد المنطقي. وهنـا لابد من توضديتح كل ذلك (1) (1): أ. عملية التمديز

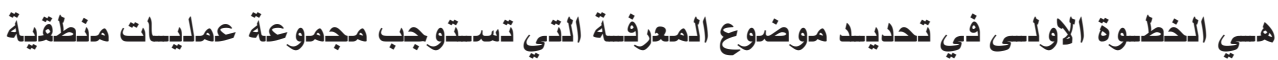

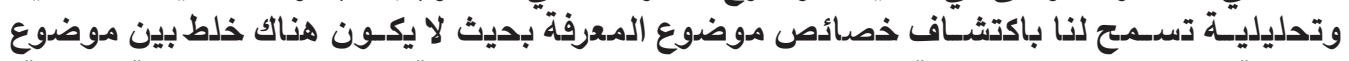

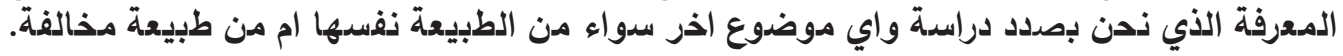

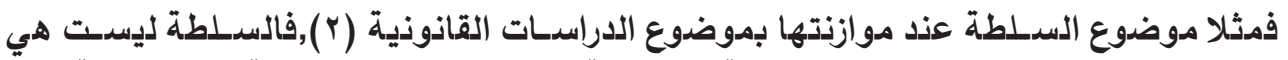

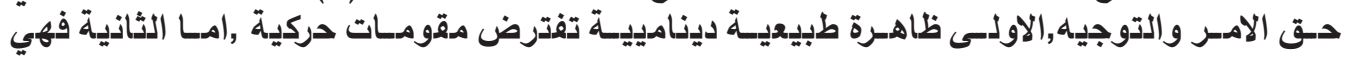

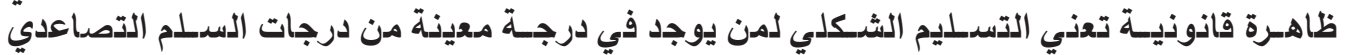

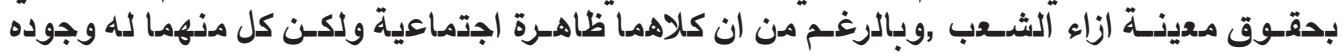
المسدتقل وطبيعة مخالفة معنة. ب-عملية الفرز(التنقية) كل معرفـة تسدعى لان تكتسـب الطابــع العلمـي يجـب ان تنقى مدـا يختلط او يرتبط بها من 


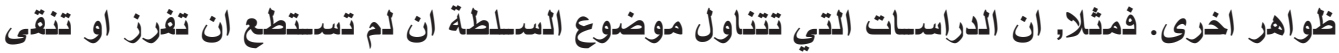

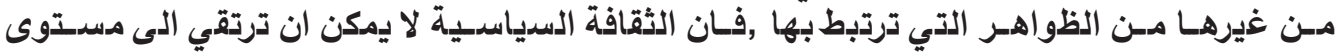

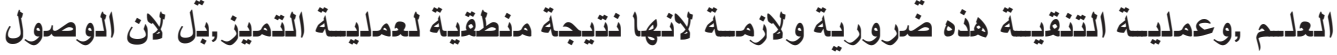

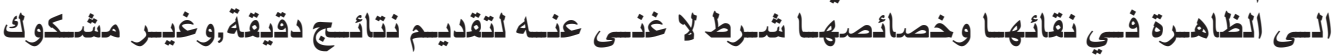

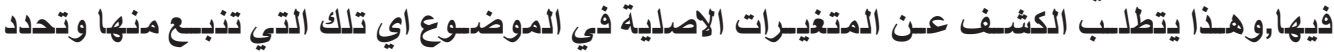

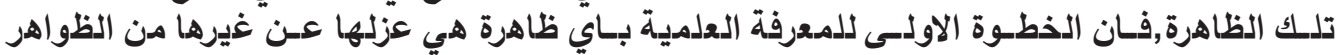

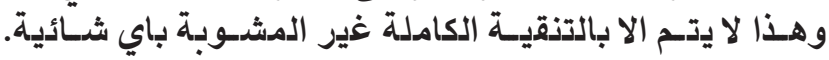

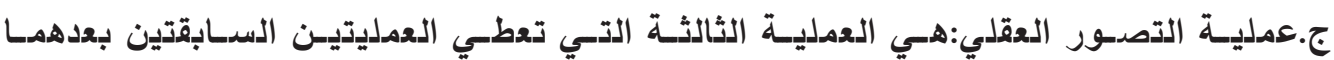

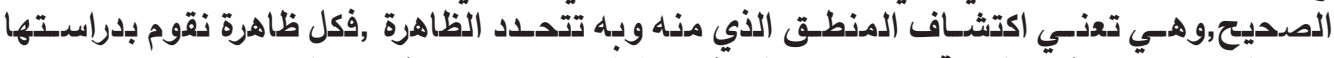

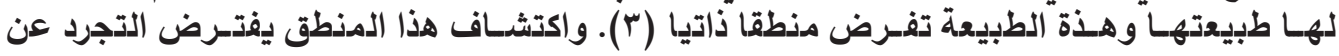

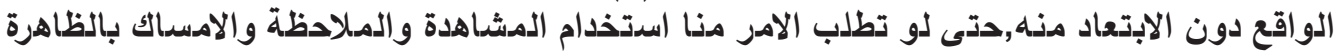

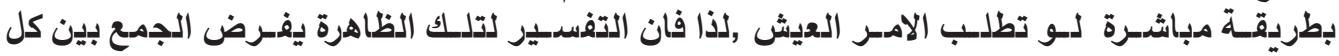

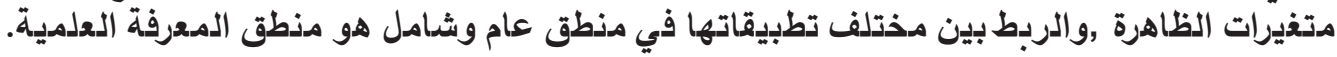

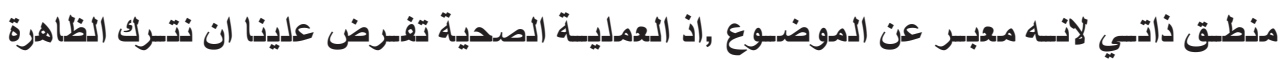

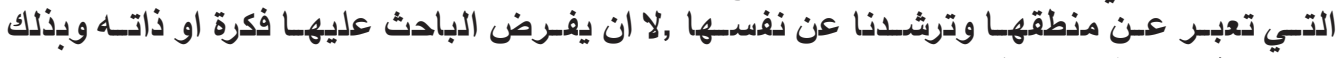
تصبتح ذات منطق دخيـل علئ عليها.

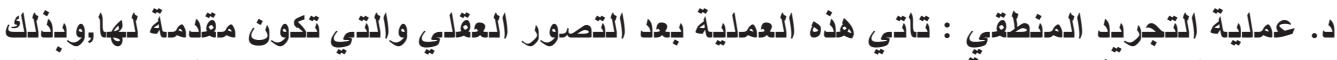

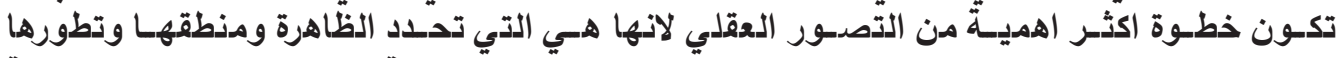

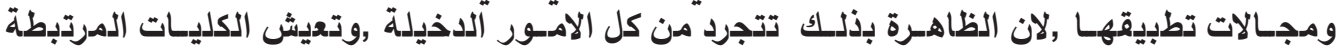

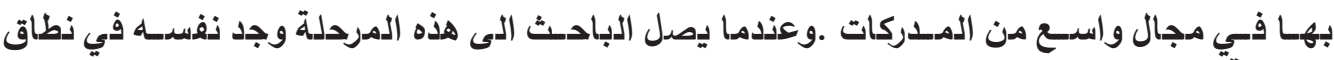

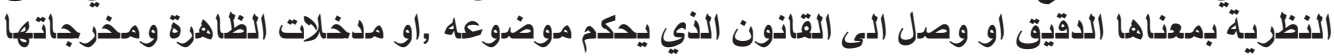

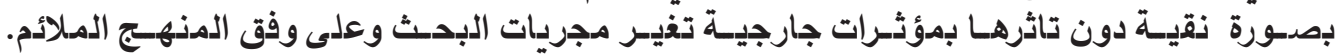

\section{ثانيا:العملية المنهاجية وخصائص التحليل}

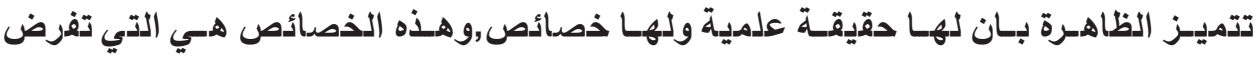

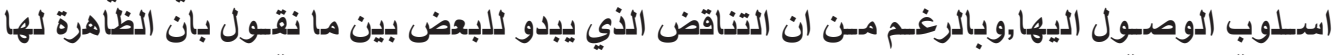

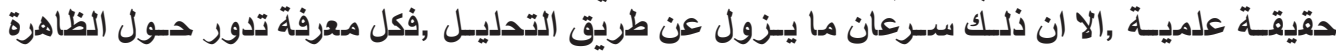

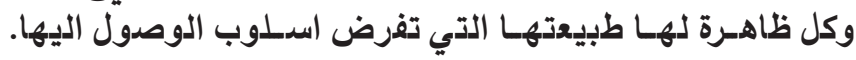

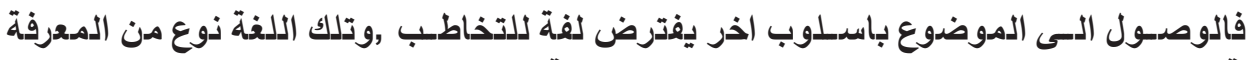

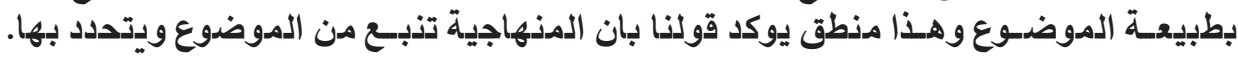

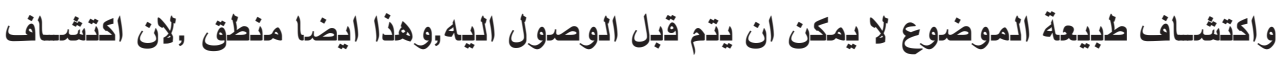

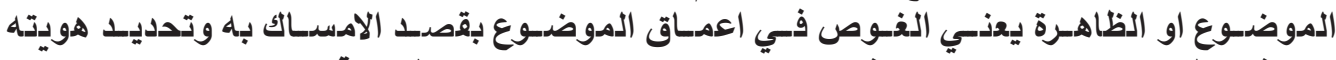

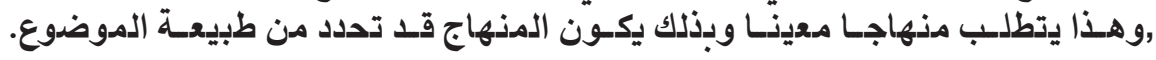

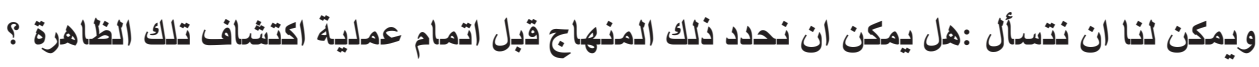

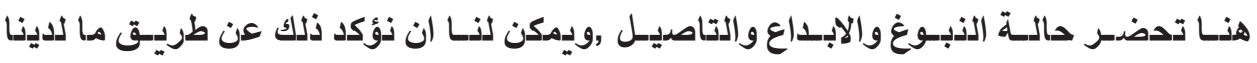




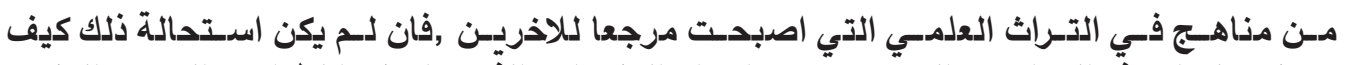

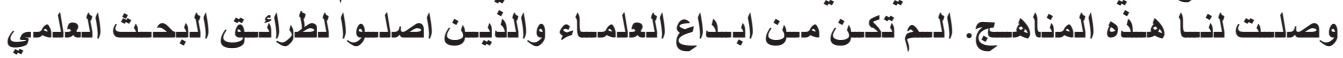

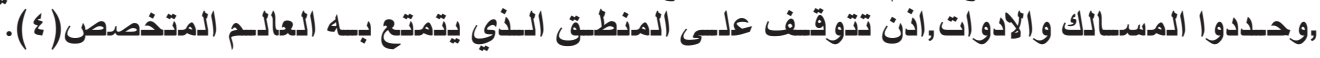

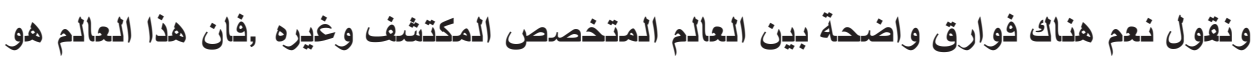

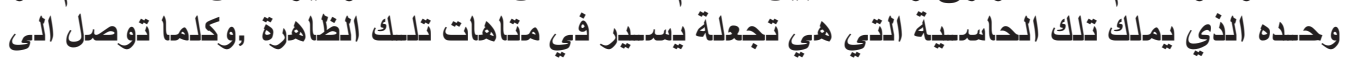

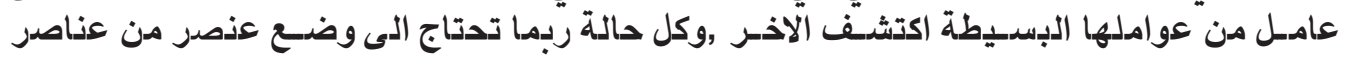

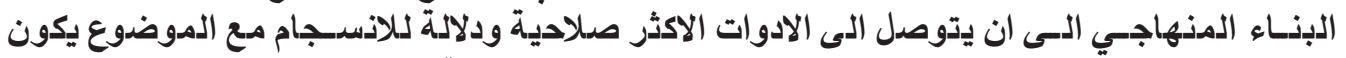

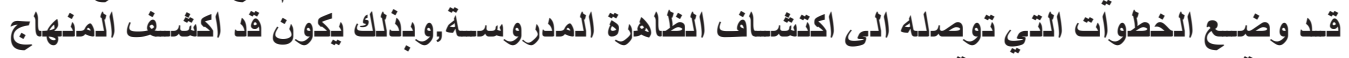

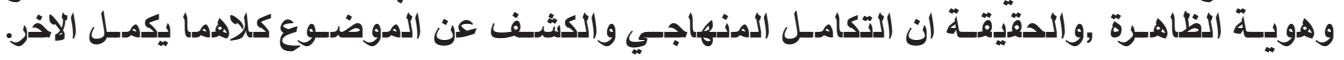

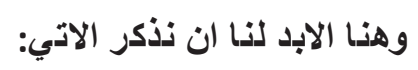

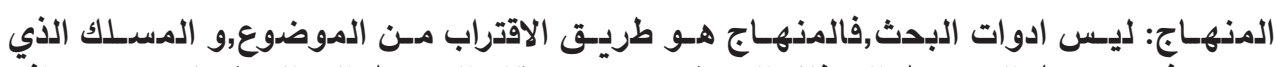

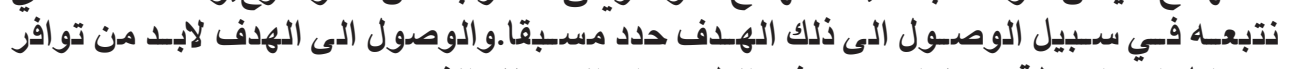

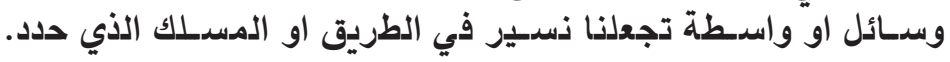

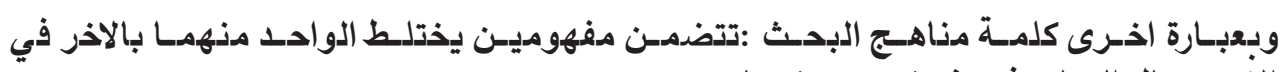

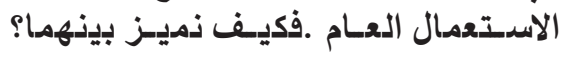

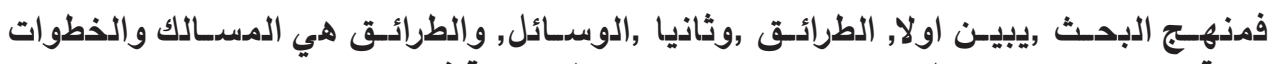

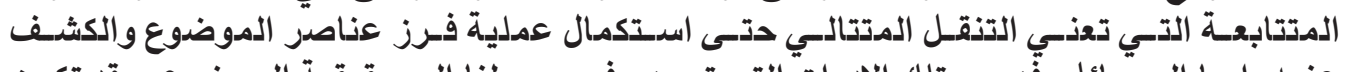

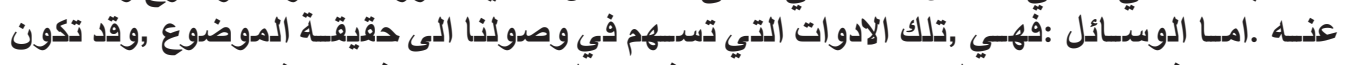

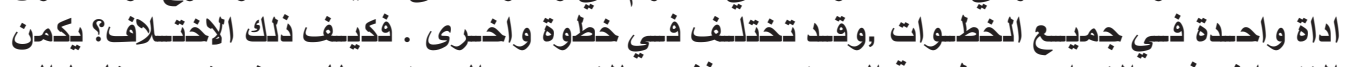

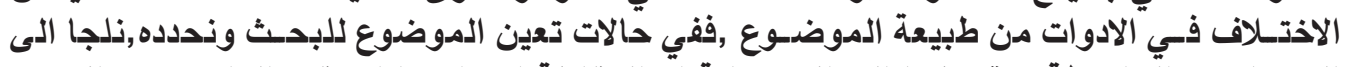

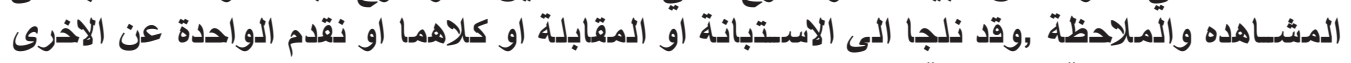

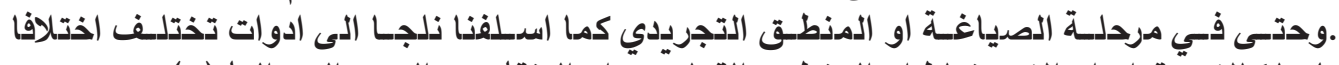

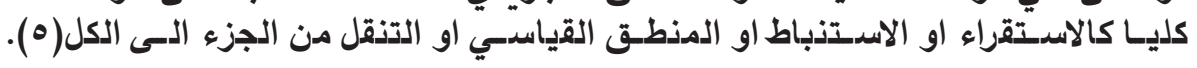

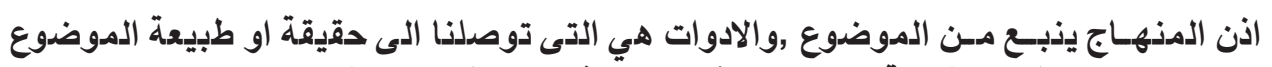

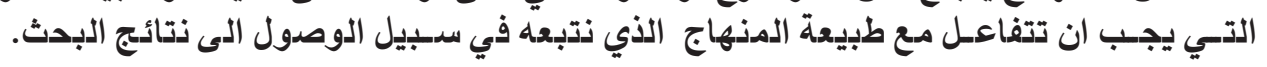
وهنا تتحدد امامنا علاقة ثلاثية الارتباط:

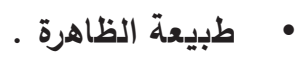

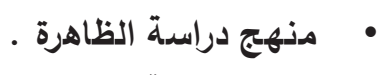

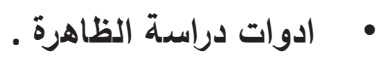
ولكن كل هذه الارتباطات تكون مستقلة عن بعضها رولكن كل واحدة تؤثَر بالاخرى.

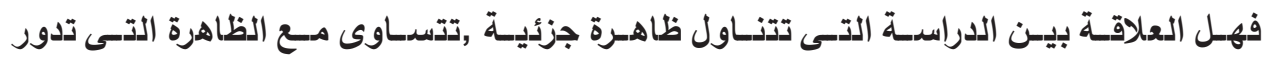

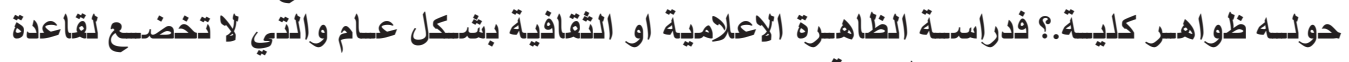

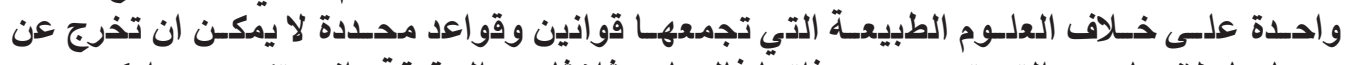

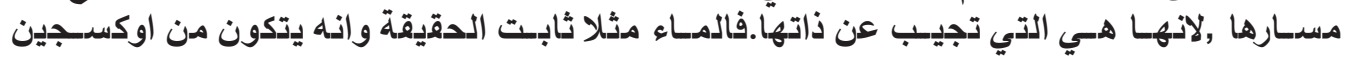




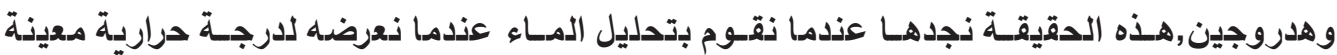

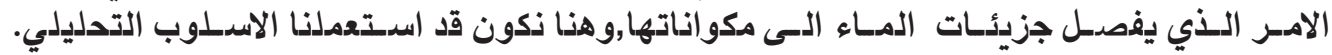

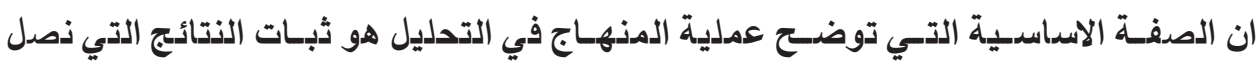

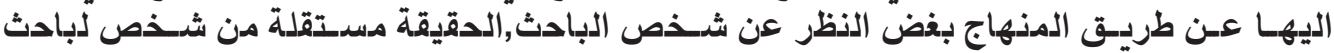

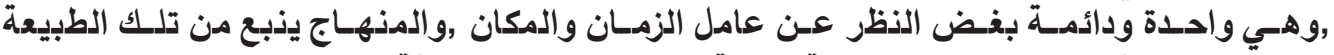

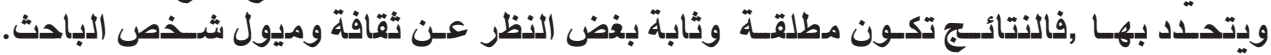

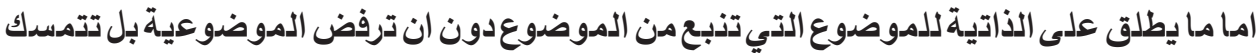

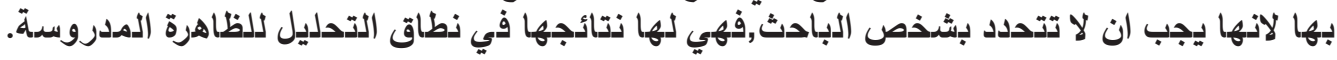

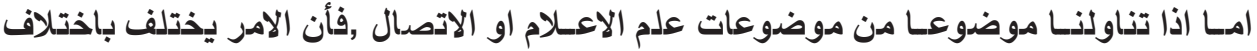

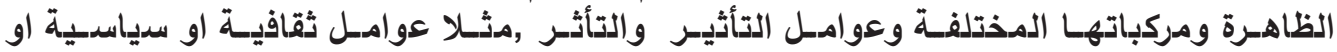

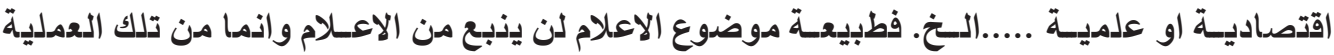

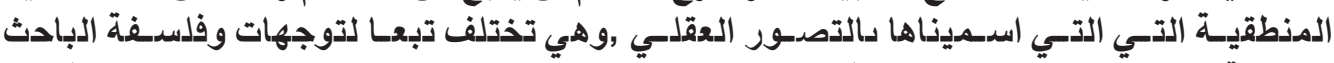

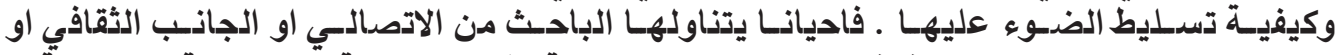

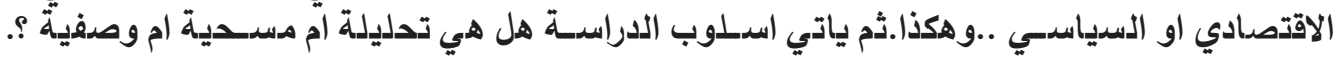

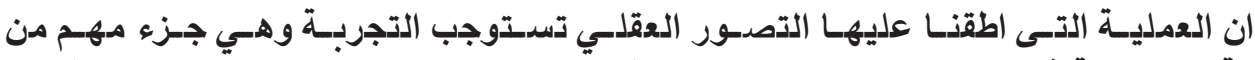

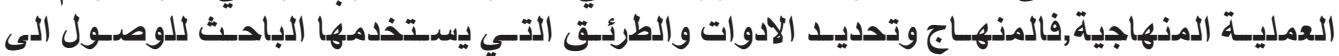

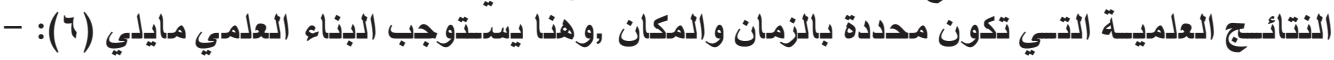

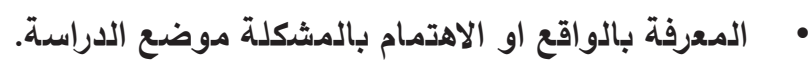
• التفكير والاستدلال الذي يعبر عن تلك المشكلة.

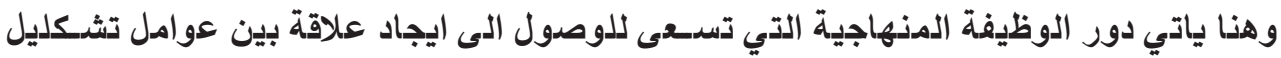

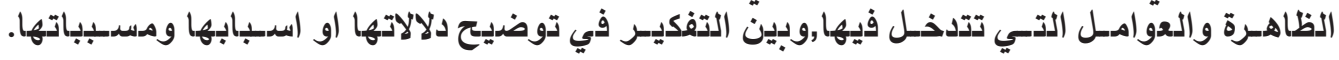

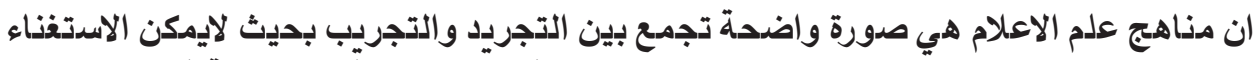

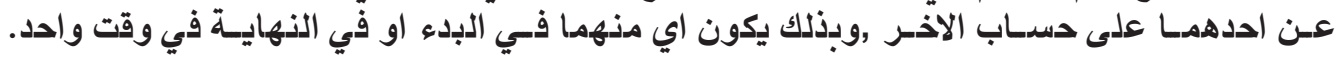

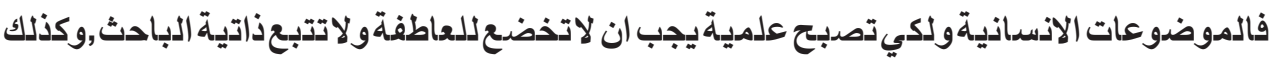

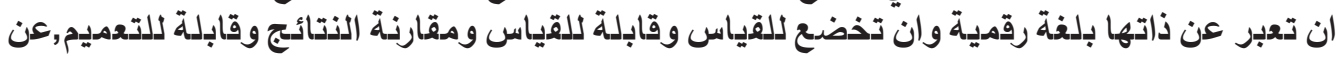

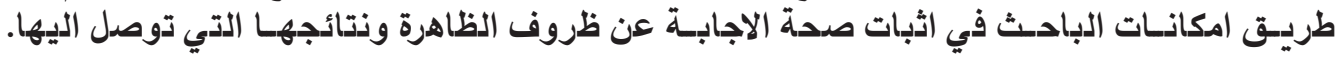

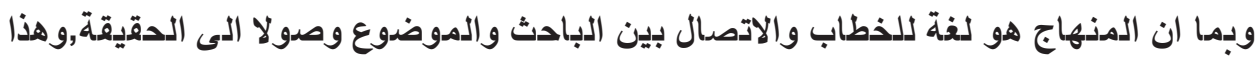

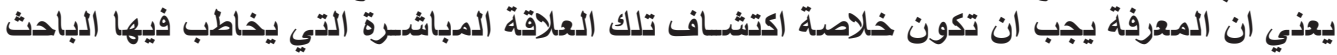

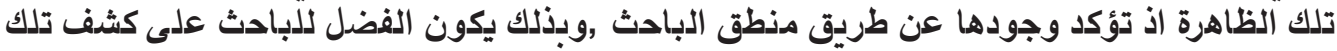

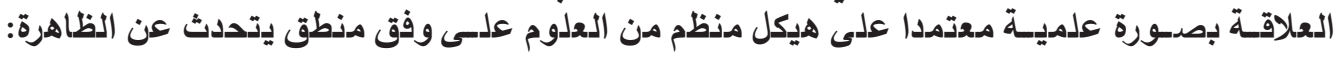

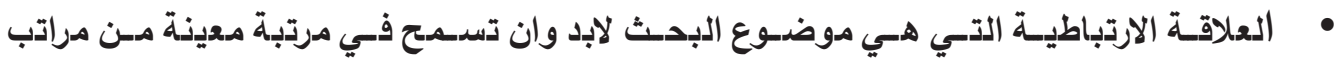

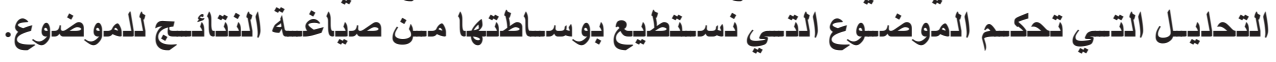
تساعدنا هذه النتائج من اكتشاف منطق عام ينبع من تلك المشكلة او الموضدوع حتى وان يكون

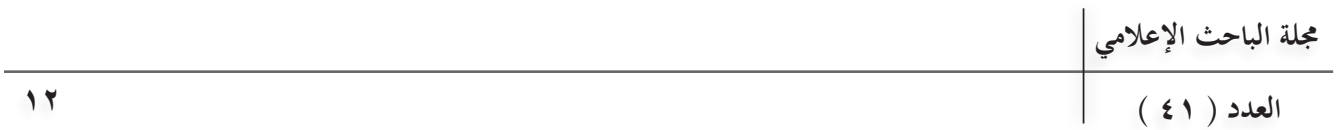


قاذونا علميا فهو تلخيص لحقيقة ثابتة روهنا يتجسد الذبوغ او الابداع الفكري لدى الباحث .

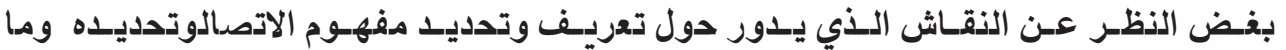

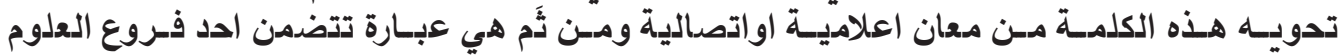

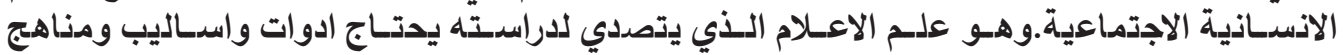

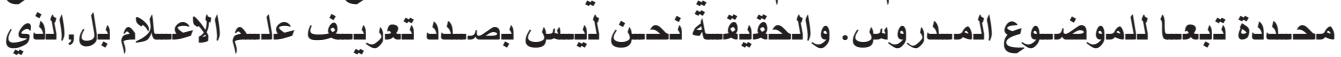

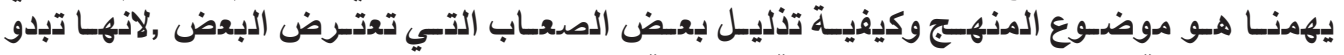

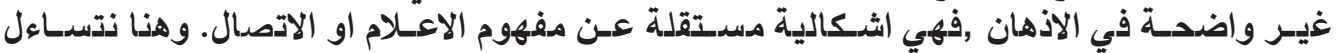

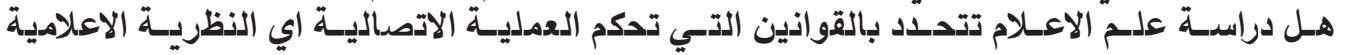

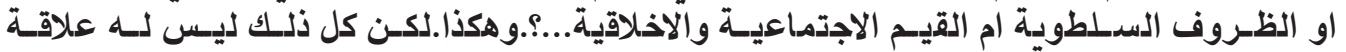

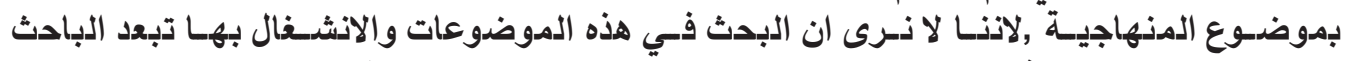

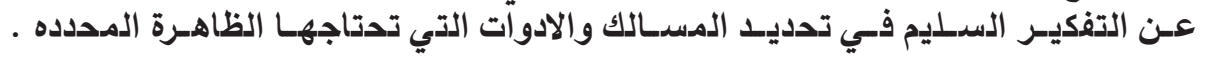

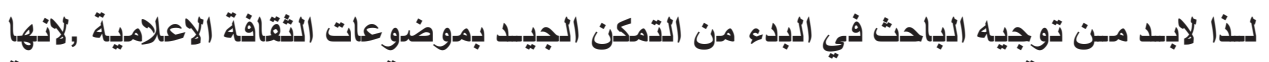

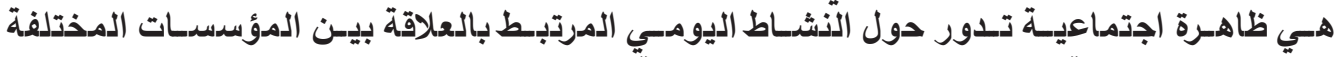

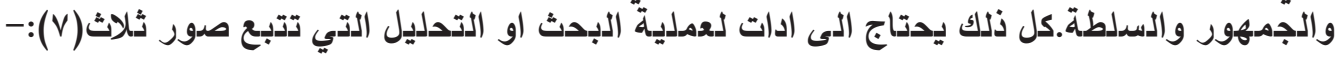

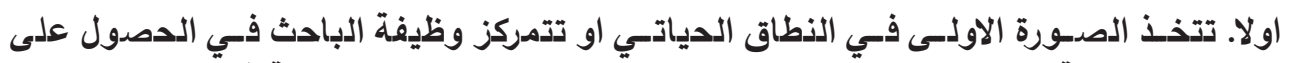

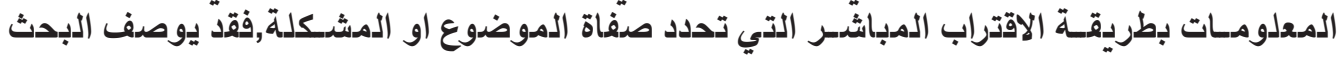

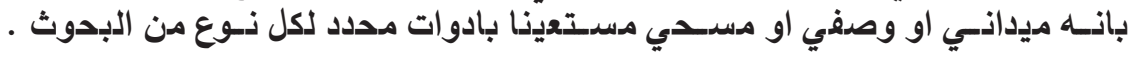

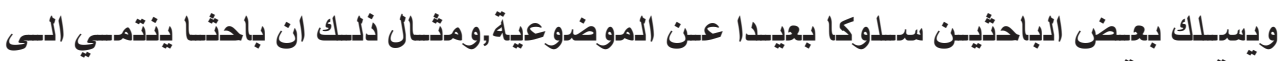

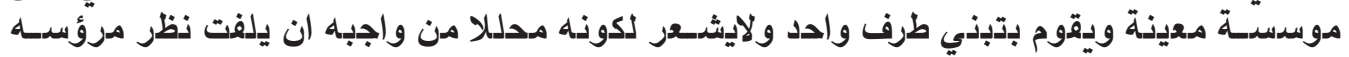

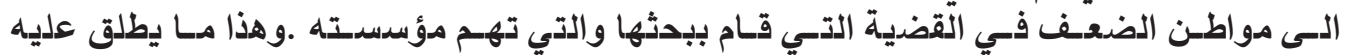

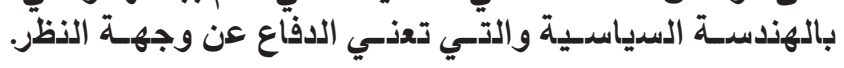

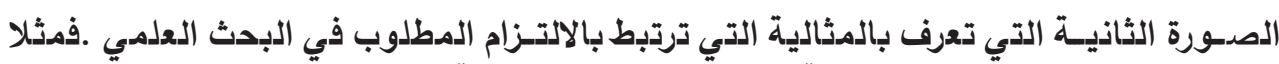

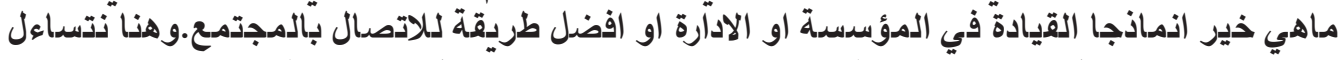

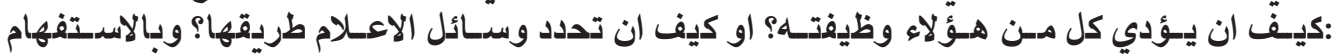

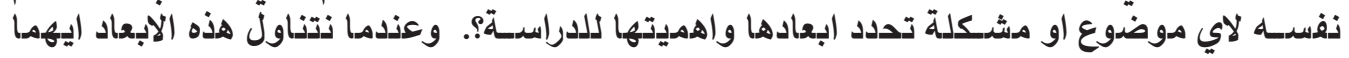

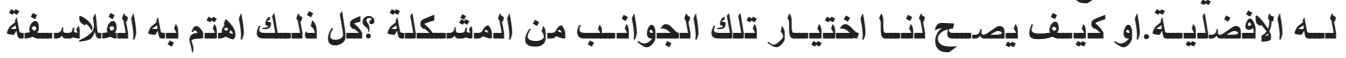

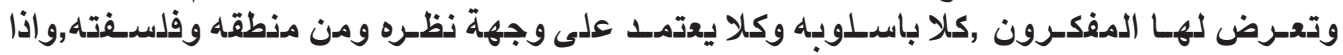

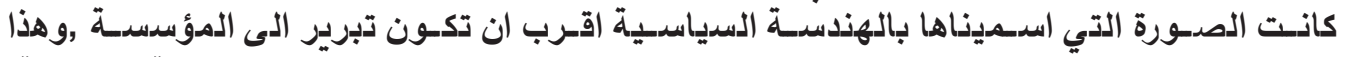

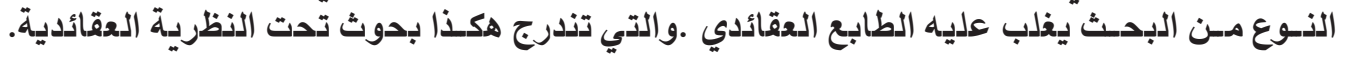

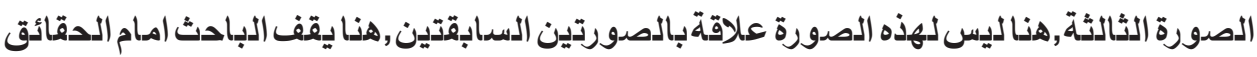

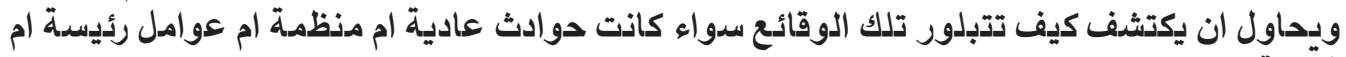

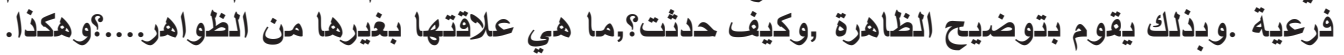

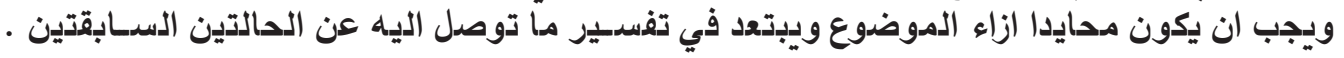

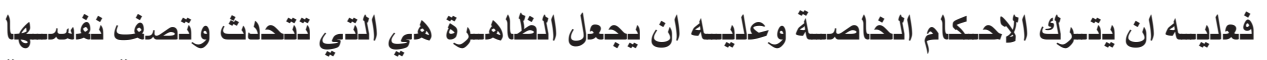

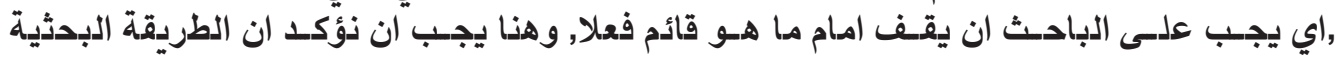


التحليلـة هـي امتــاد للنظرية التجريبـة روالذي يدعم طرحناعلـى وفق الاتي(^):

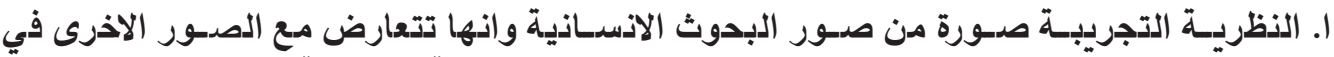

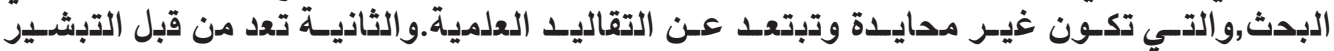
وليس علـم تحليل يتبـــع الادوات والاخـلاق العلمية.

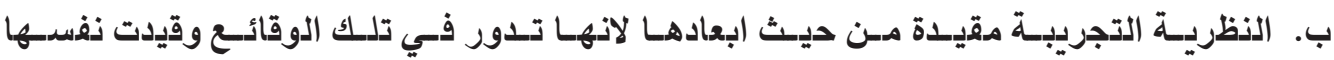
بالظاهـرة وّلا تخـرج عـن النطـاق المحدـد لها.

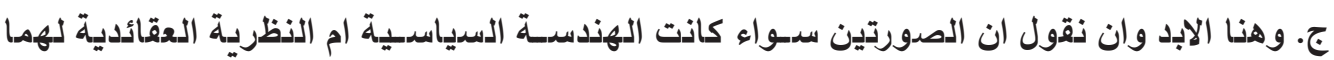
دورهمـا في توضيح نطاق الوجود السياست الصدي او الدركسي العام في المجتمع.

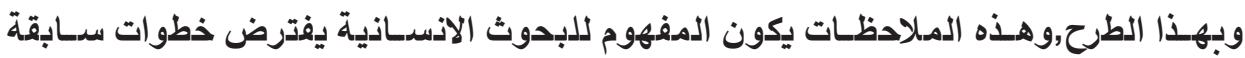

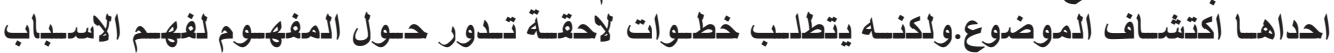

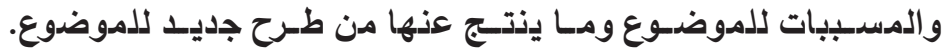

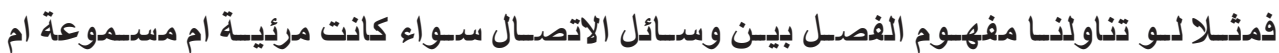

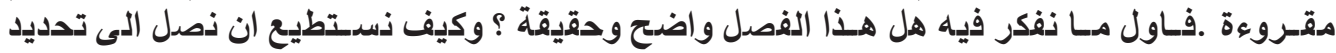

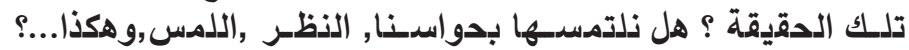

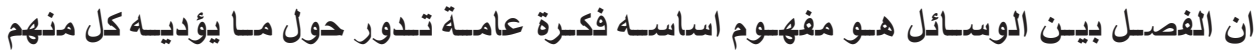

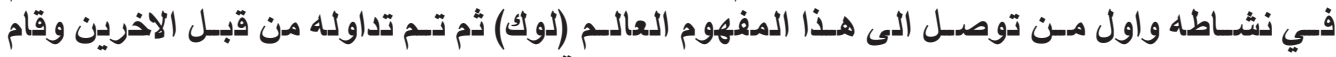

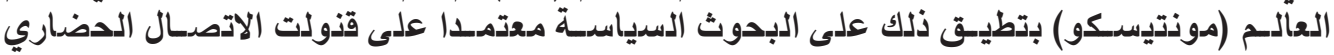

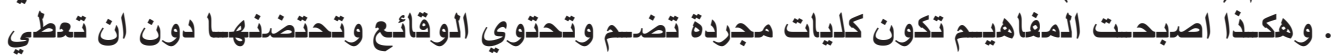

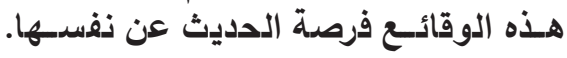

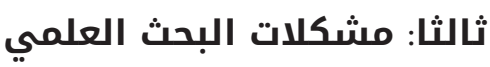
1- العلاقة بين المشكلة والمدتوى

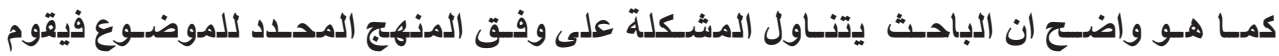

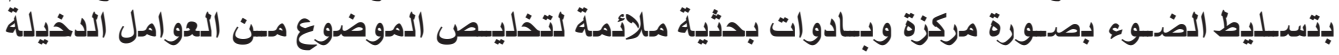

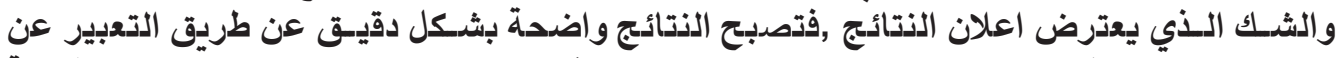

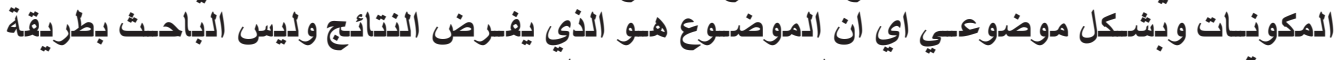

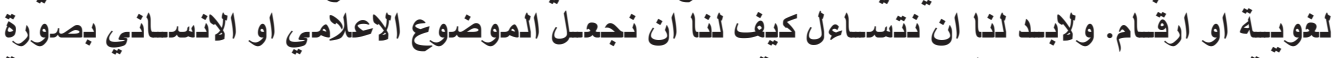

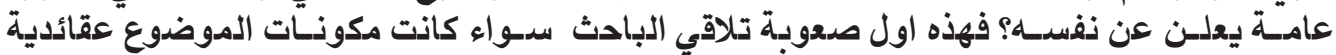
ام مذهبية.ام نشـاطا سدوكيا..وهكذا.

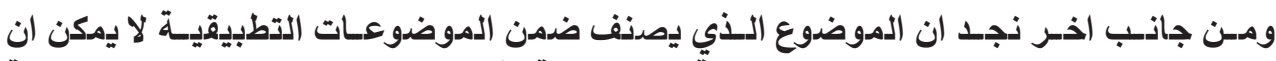

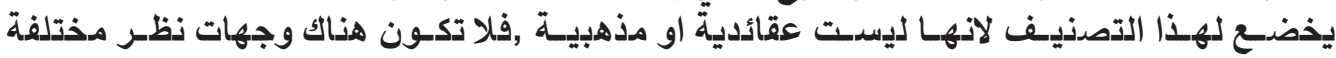

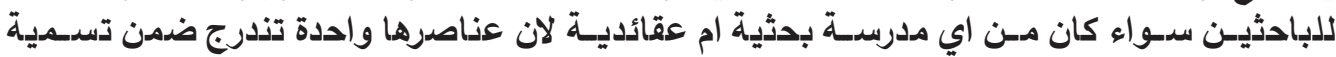

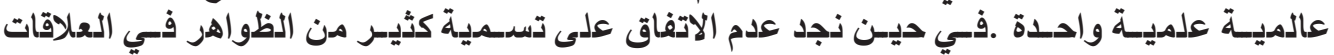

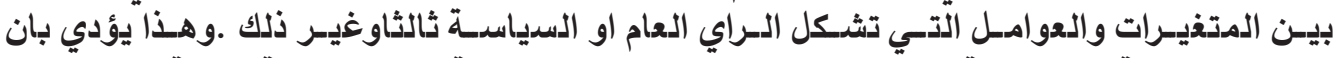

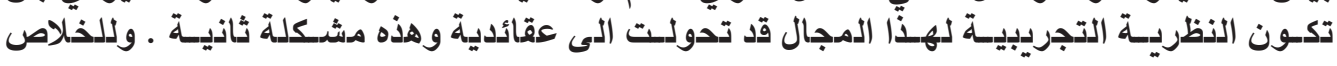




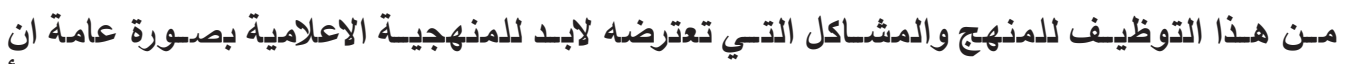

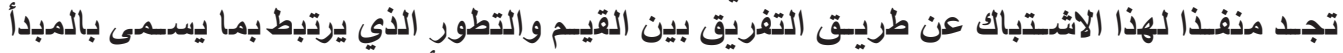

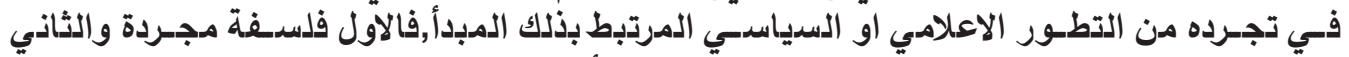

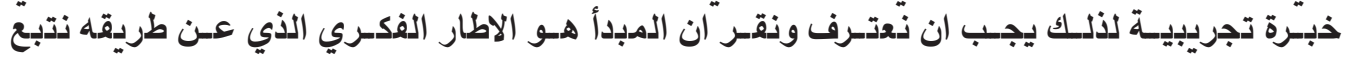

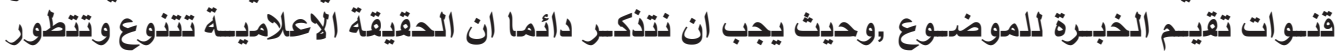

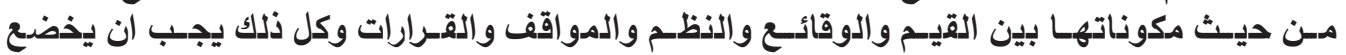

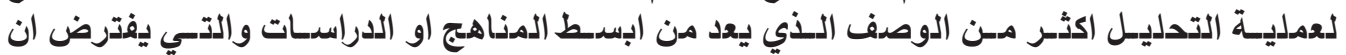

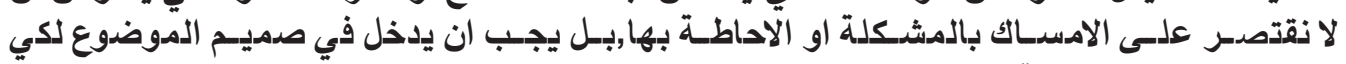

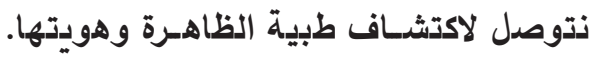

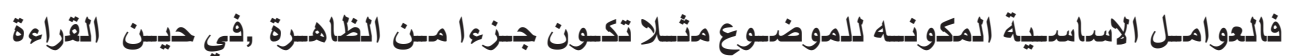

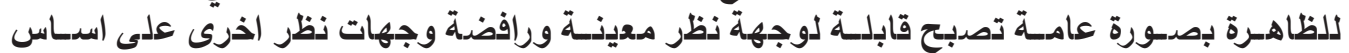

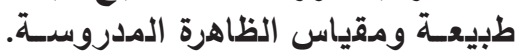

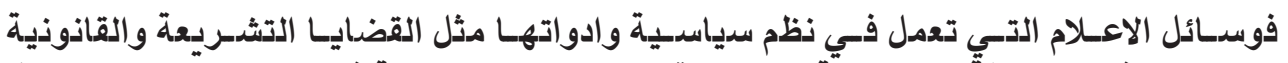

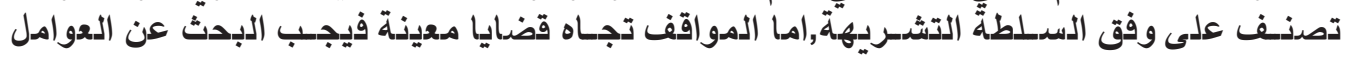

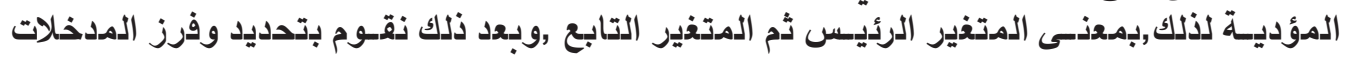

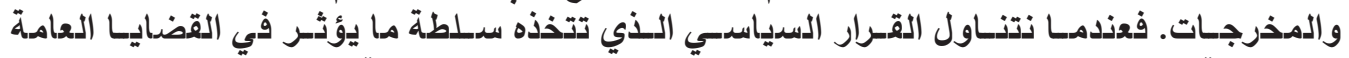

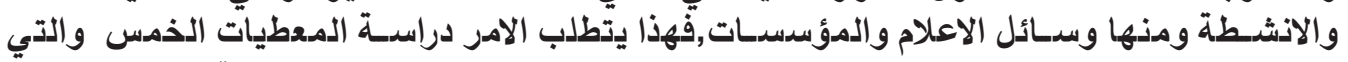

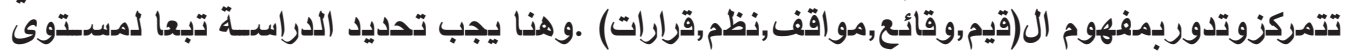

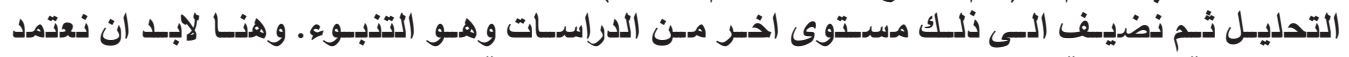

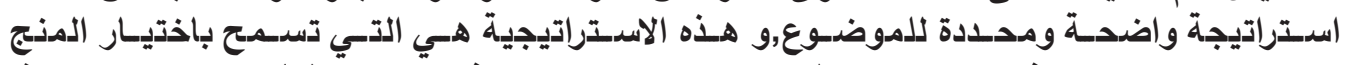

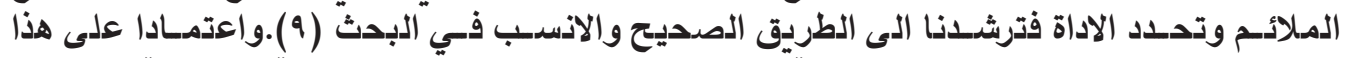

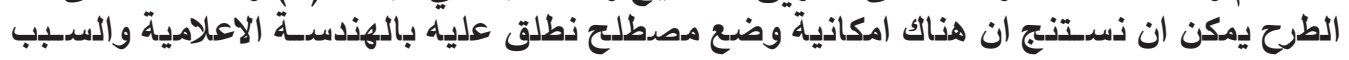

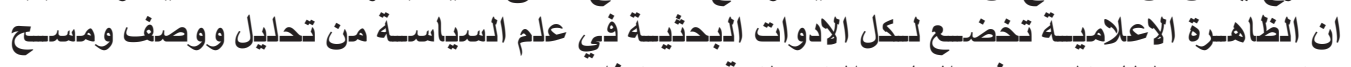

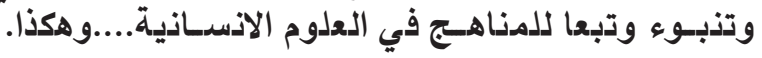

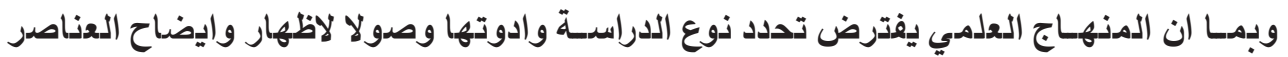

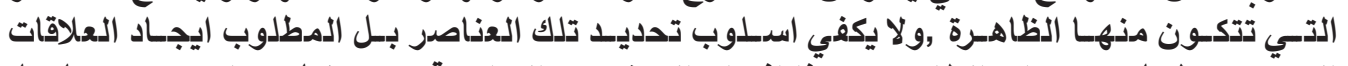

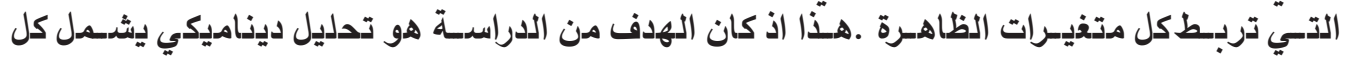

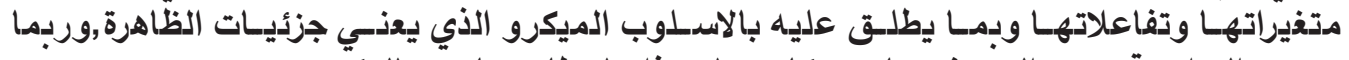

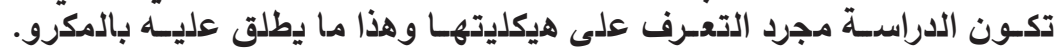
r ـ الظاهرة المدروسدة وعملية الربط بين المتغيرات :

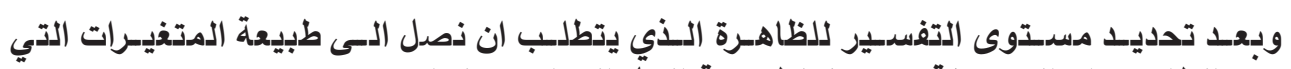

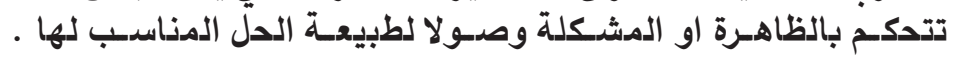

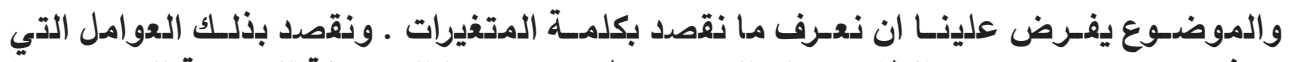

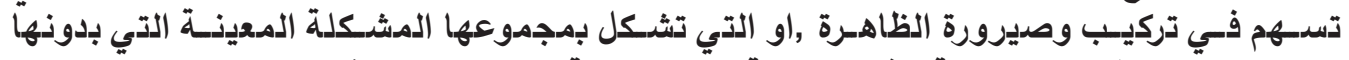

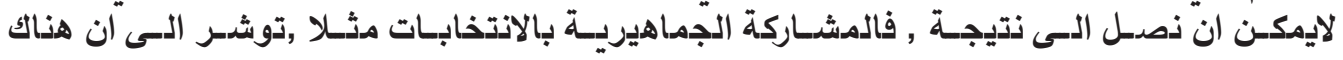




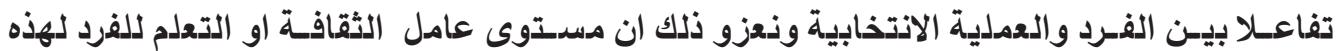

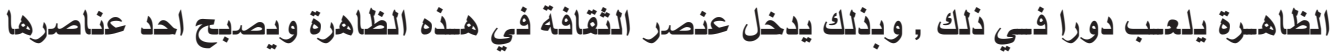

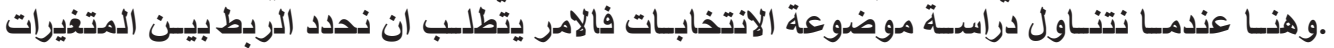

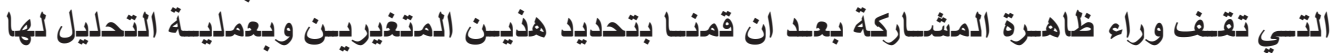

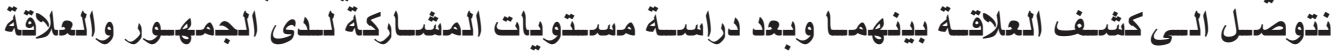

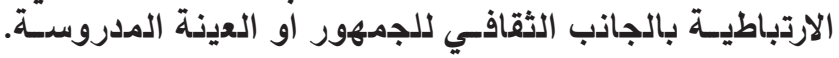

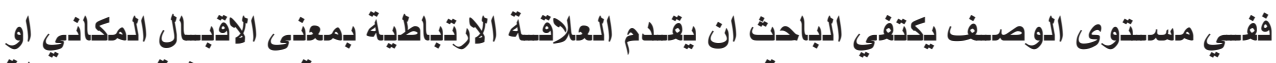

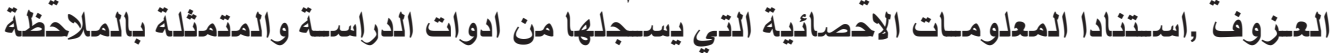

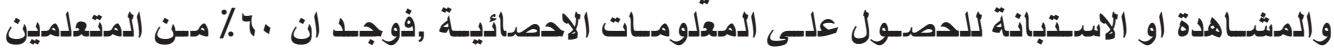

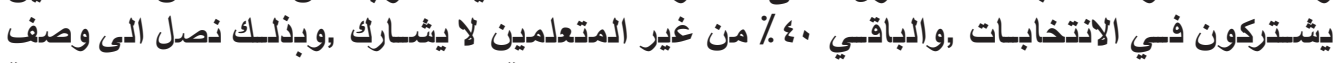

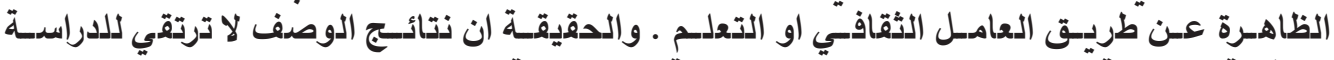

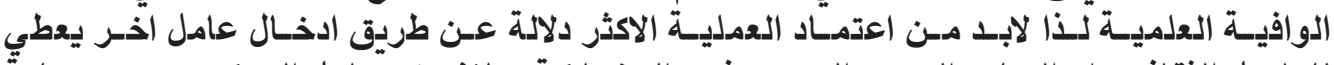

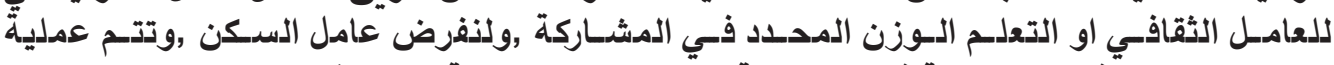

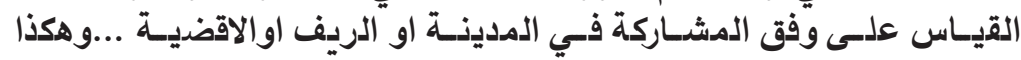

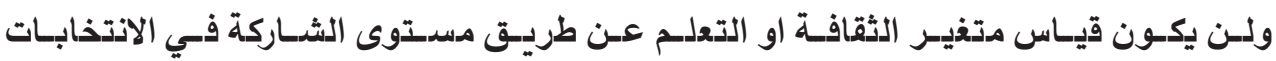

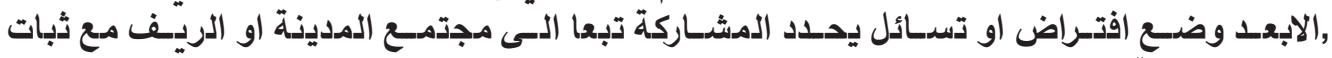

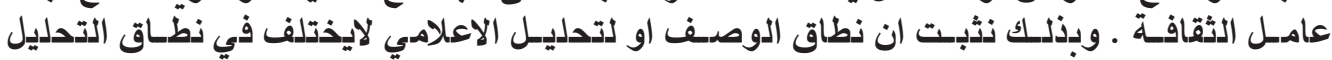

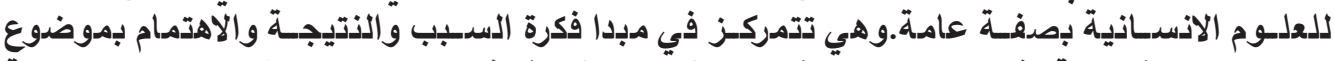

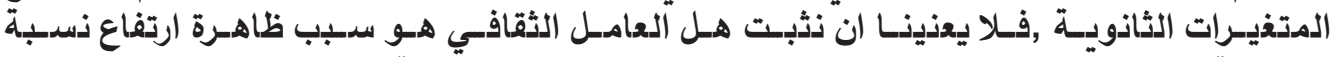

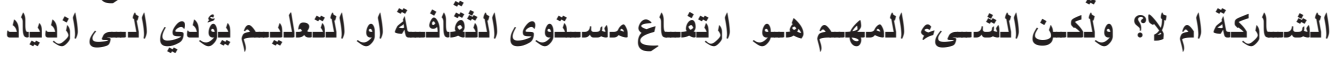

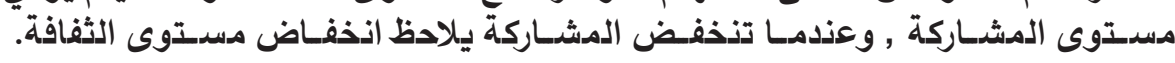

\section{رابعا: اهمية المناهج في الموضوعات الاعلامية}

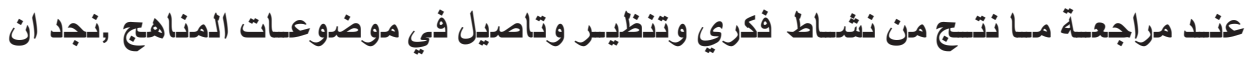

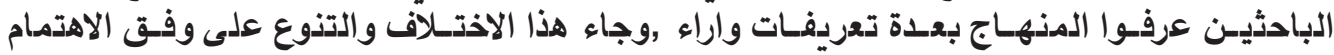

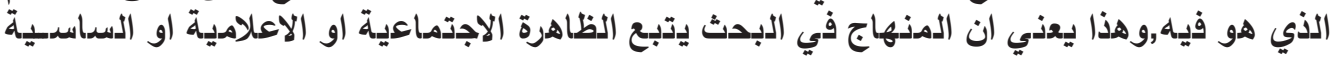

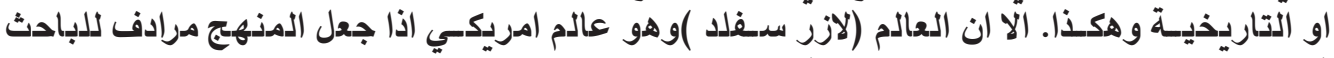

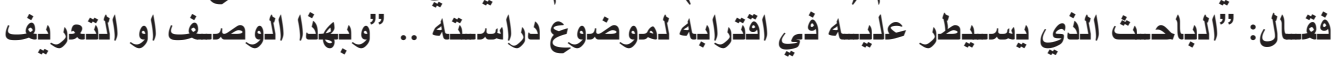

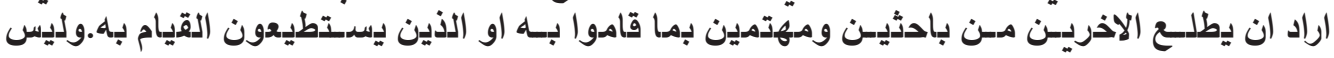

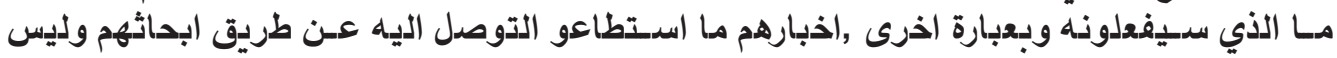

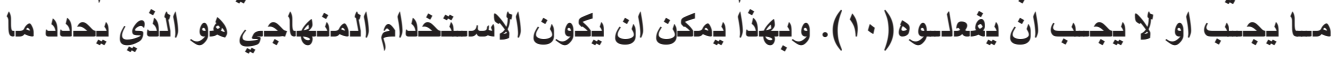

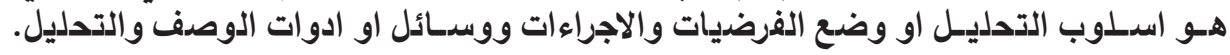

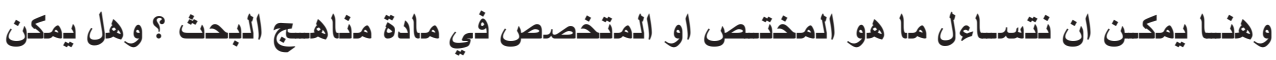

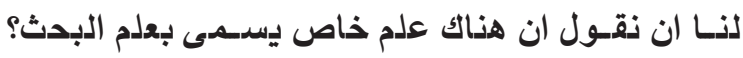

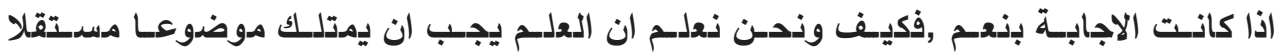

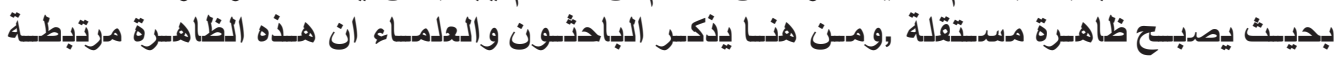

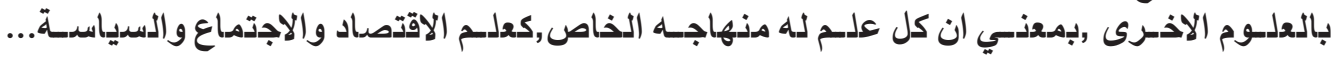




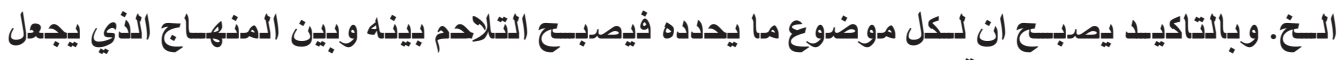

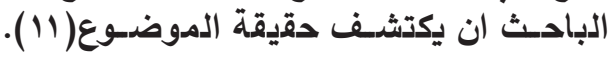

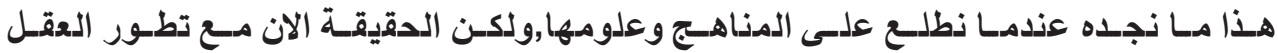

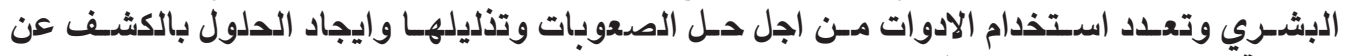

$$
\text { حقيقـة الامسر والتسي تكمن فــي واحدة مـن الآتي:- }
$$

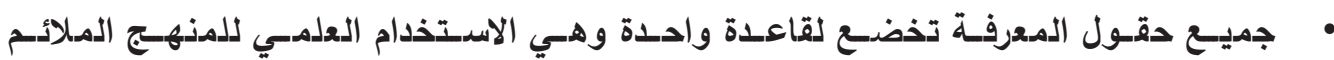

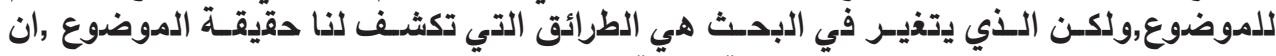

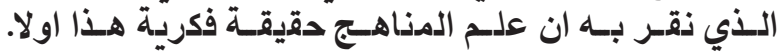

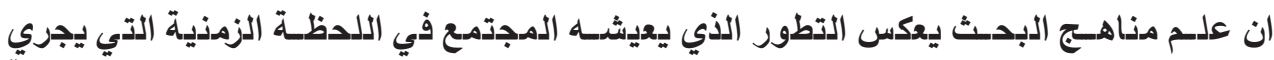

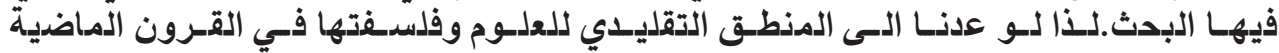

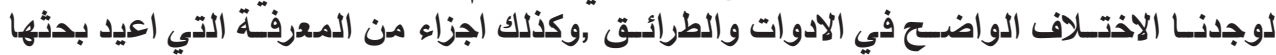

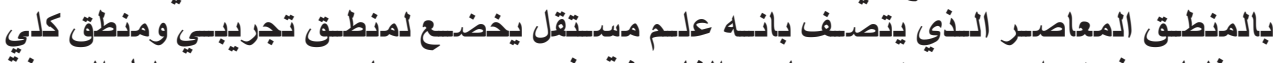

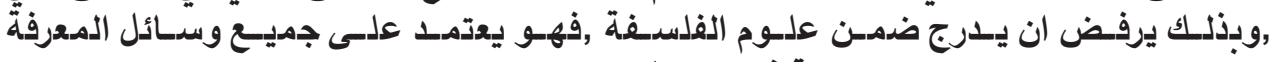

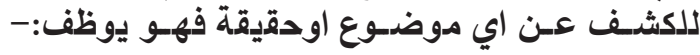

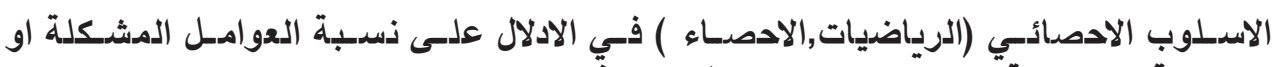

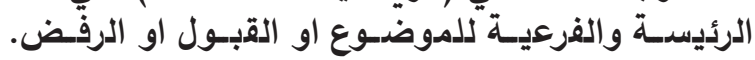

اسدتخدام المنهج او الاسدوب التجريبي الذي تعتمد عليه العلوم الطبعية,الملاحظة,المشاهدة.

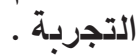

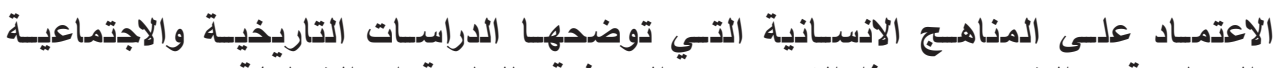

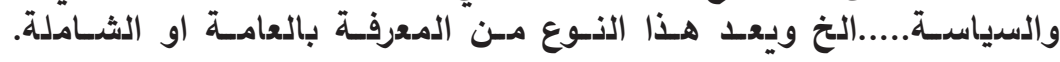

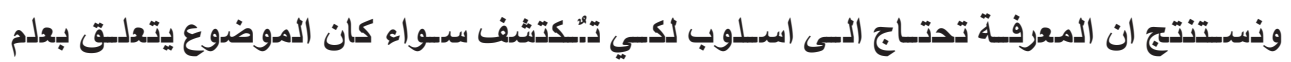

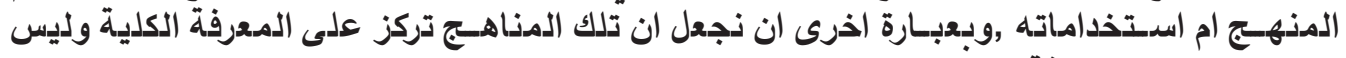
علسى ذوع مـن المعرفة الخداته

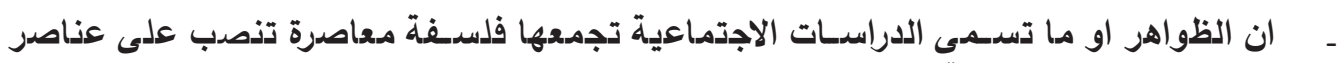

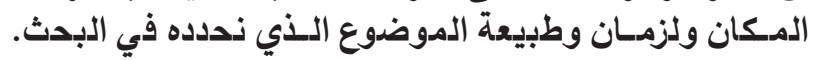

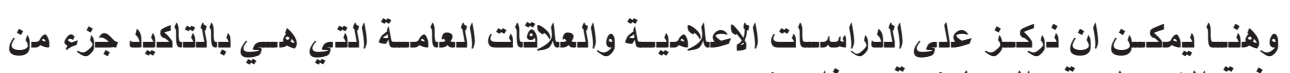

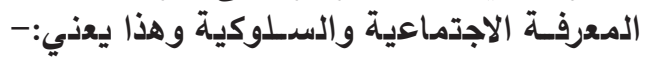

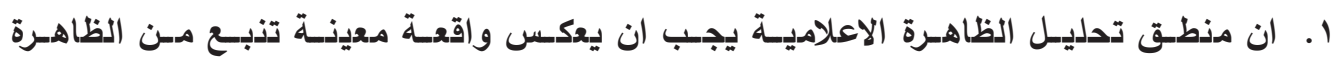

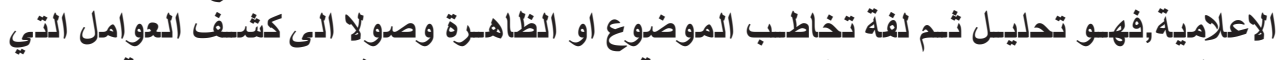

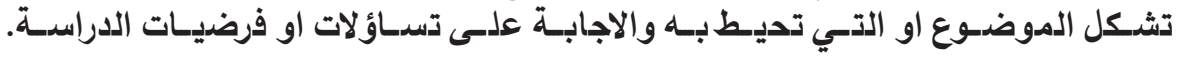

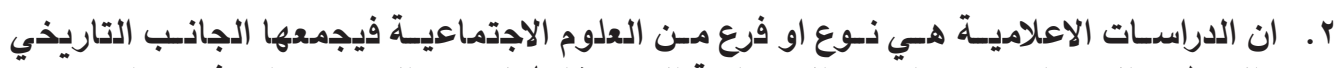

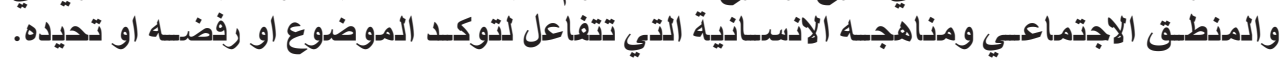
r. ت توظيف المنطق العلمي من اجل البحت عن الحقيقة باستخدامنا جميع مظاهر التقدم المعرفي 


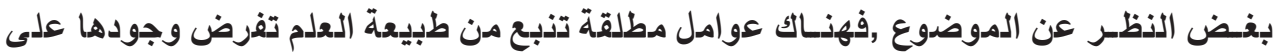

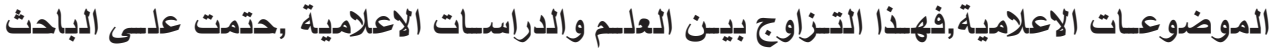

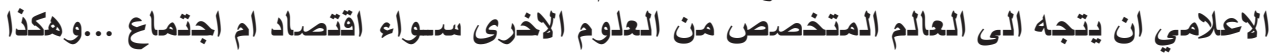

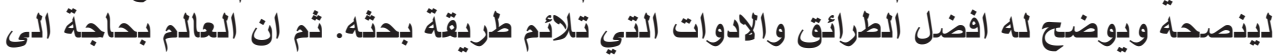

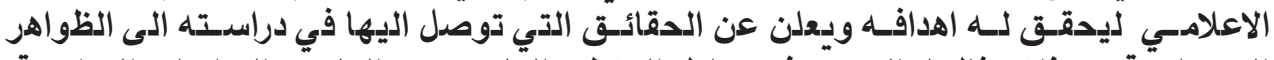

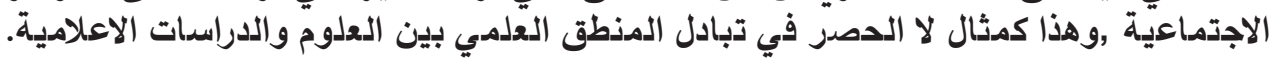
ع. ت تتطلب بعض الدراسدات الاعلامية اسدتخدام اسدلدب التجريب والتجريد بمعايير متقاربة اسدوة

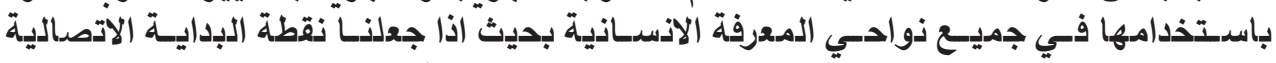

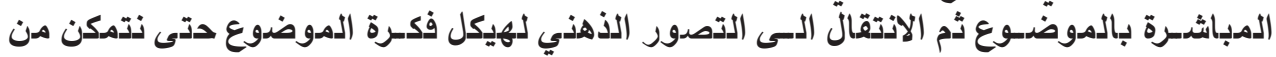

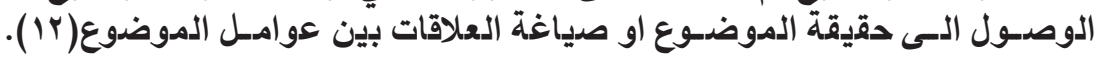

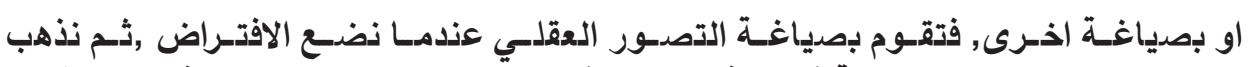

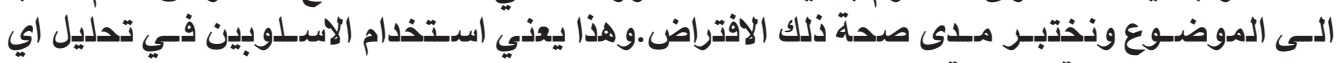
موضدوع او مشكلة الـوضئة اعلامية.

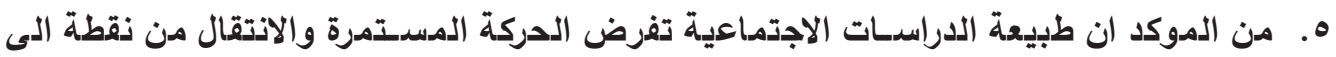

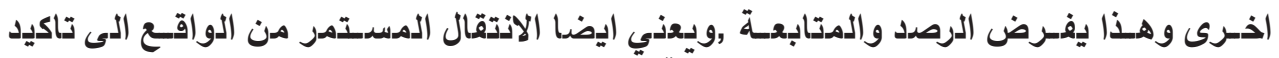

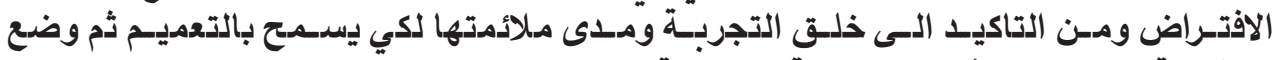

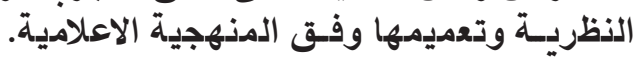

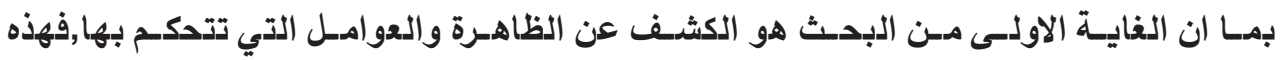

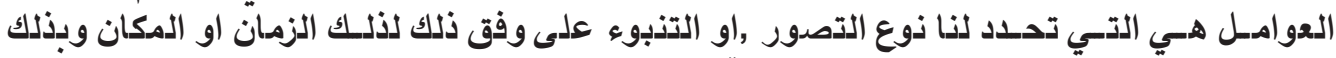

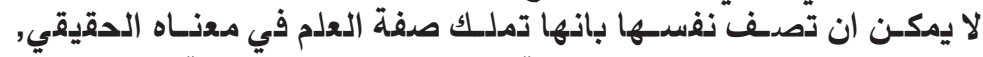

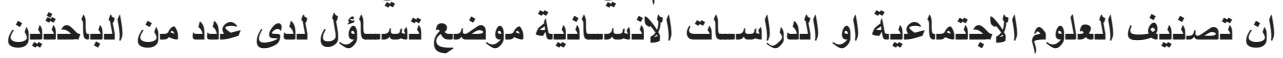

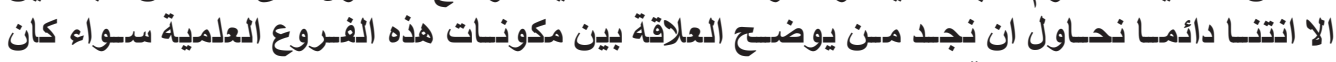

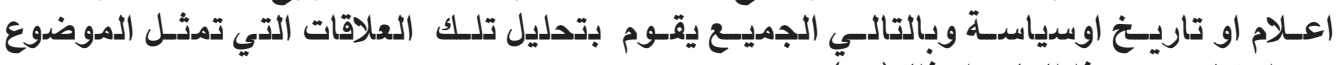

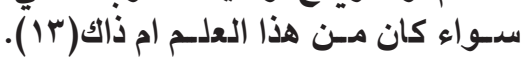

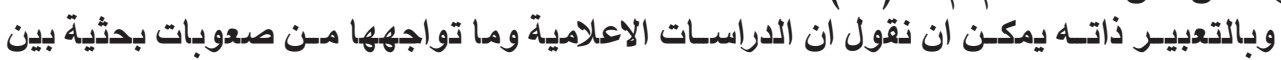

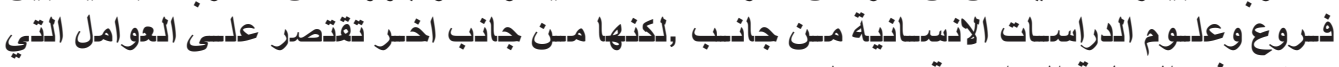

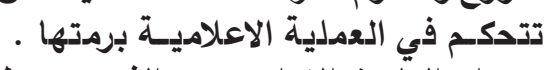

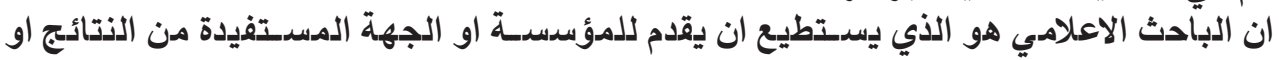

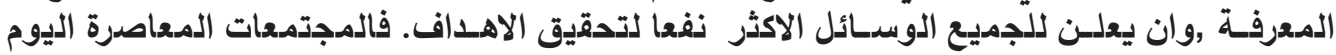

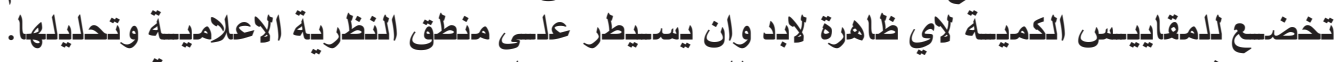

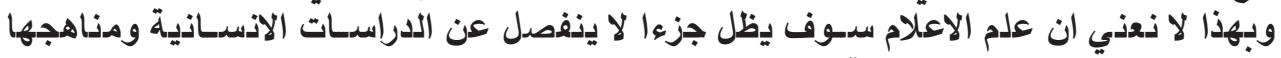

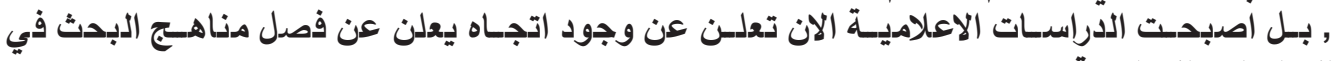

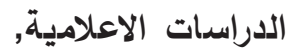

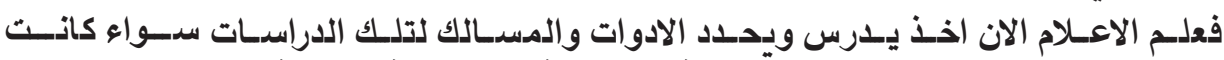

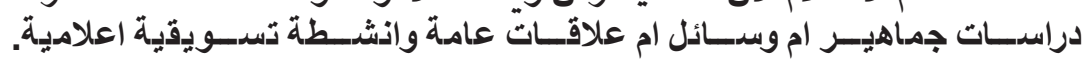
ويعود هذا الفرز والتطور للدراسدات الاعلامية ما يمكن ان ذسديه تجرد الدراسدات الاذسدانية,فلو 


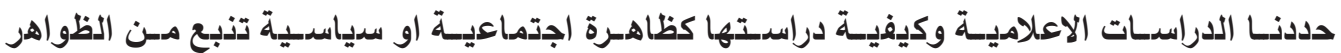

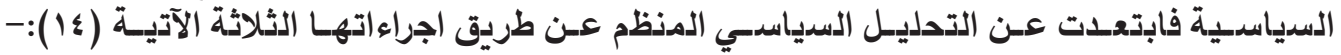
ا. ـ من الواضح جدا ان الموضدوعات الاعلامية تحلل على وفق المضدون او المشكـلات الاعلامية تخضع للتحليل والمنطق.

r . دراسدة الذظم الاعلامية وتطبيقاتها ووسدائل اتصالها.

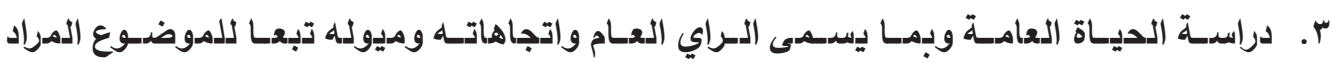

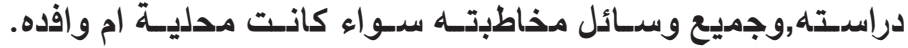

ـ. ـ دراسـة التفاعليـة والاثـر والتاثير جـراء التطور الحاصدل في جميع وسدائل الاتصال والتواصل الاجتماعي عبر شـبكات الاتصدال.

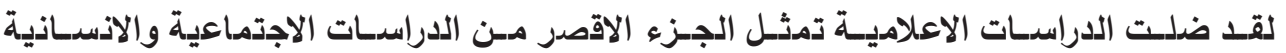

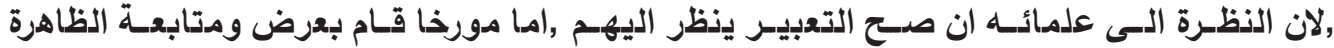

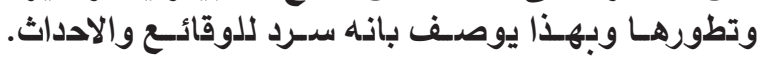

واما سدياسديا يخوض مضدمار الذظرية السياسدية وسدلـوكها روبهذا يحسدب على المدرسدة

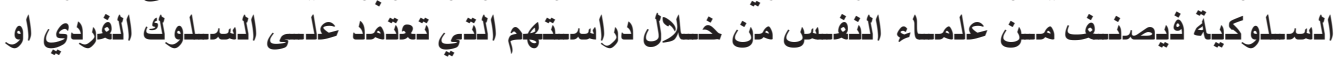

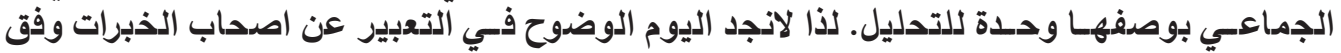

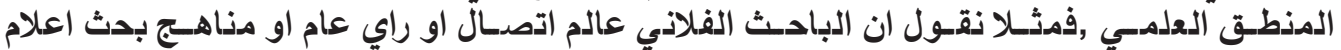

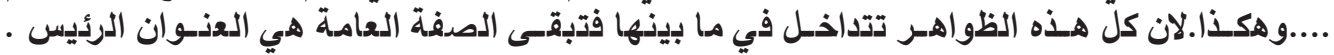

\section{خامسا: مراحل التحليل وتقسيم الدراسة تقسيم البحث}

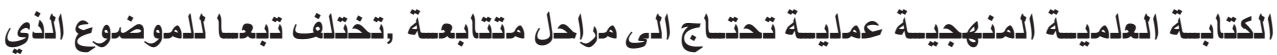

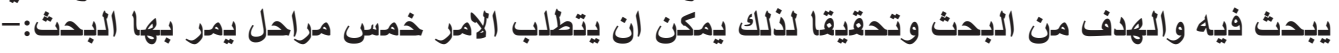

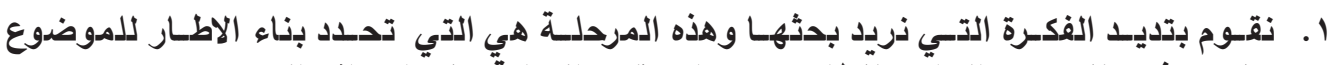

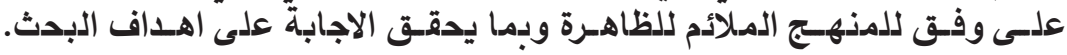

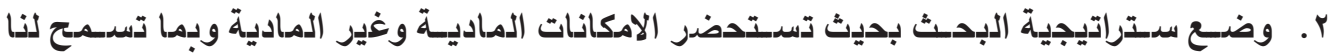

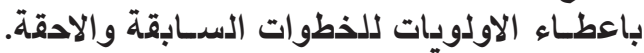

r. ت تعيـن اداة البحث او بعبارة اخرى اسدتراتيجية البحث لابد وان تمكننـا من تحديد واختيار اداة دراسدة الموضدوع اله الو تحليله.

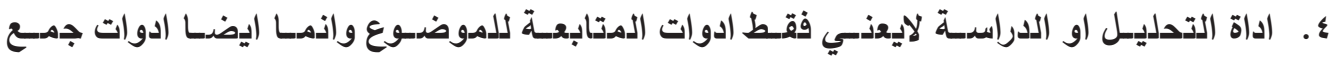

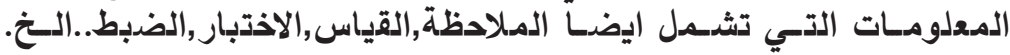

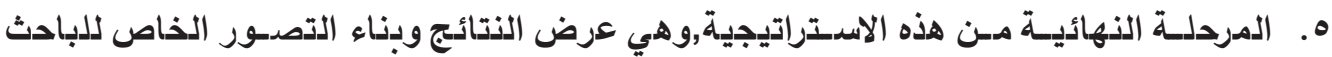

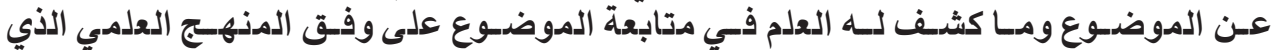

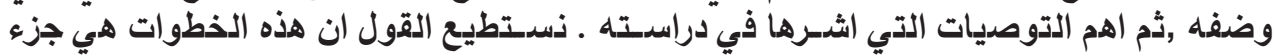




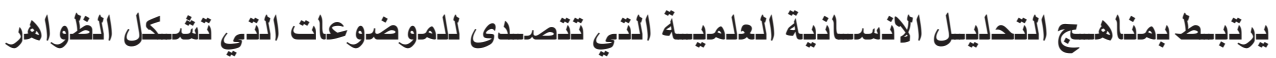

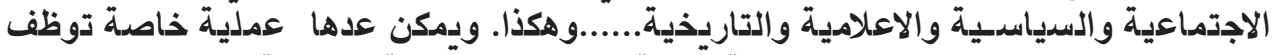

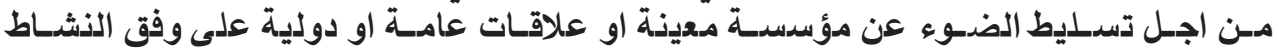

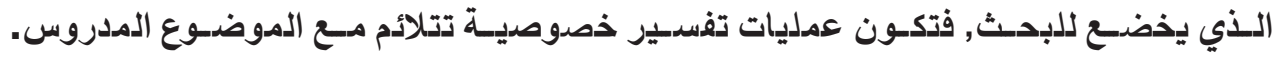

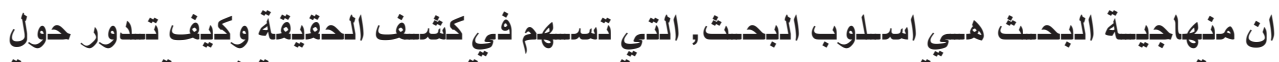

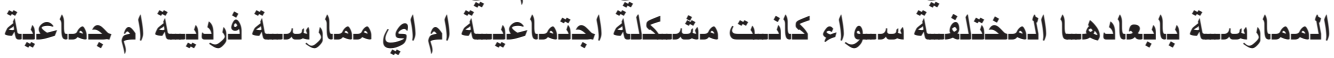

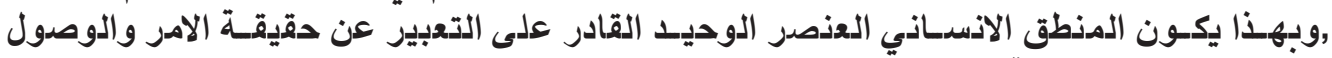

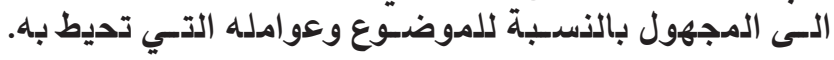

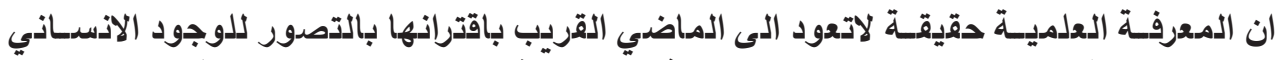

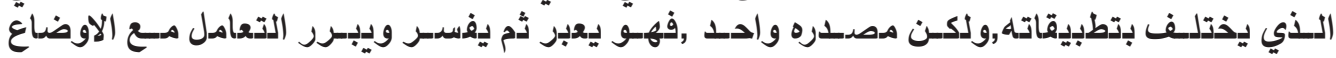

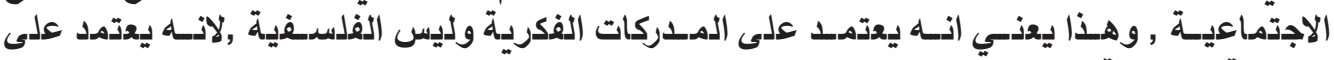

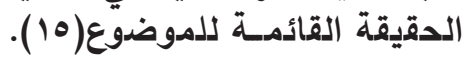

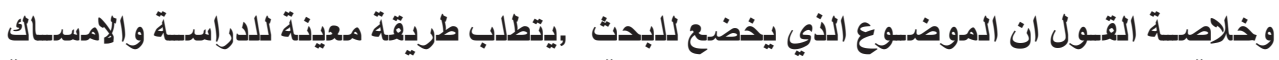

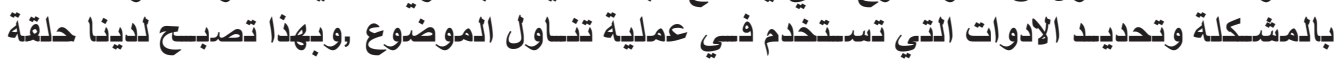

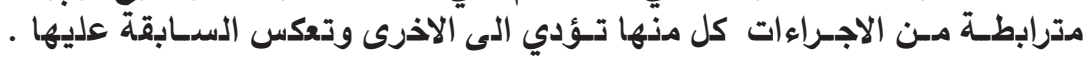

\section{سادسا: القياس في البحوث الاعلامية}

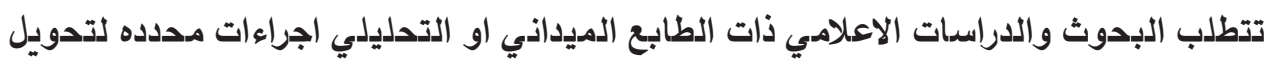

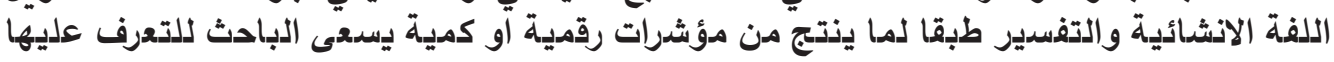

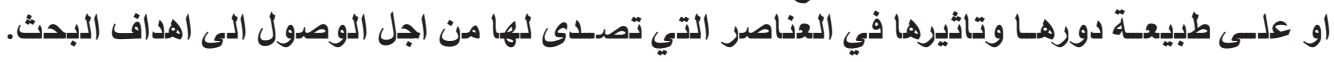

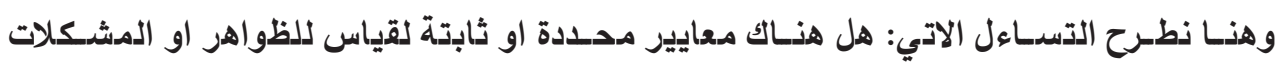

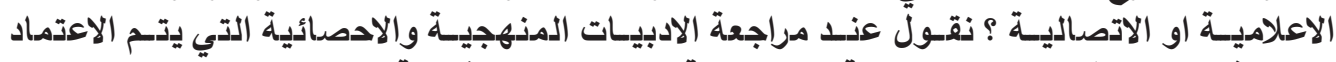

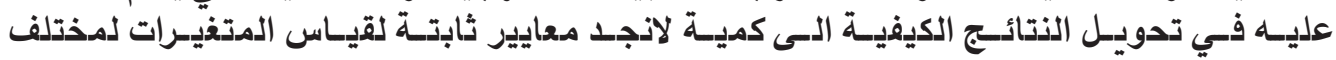

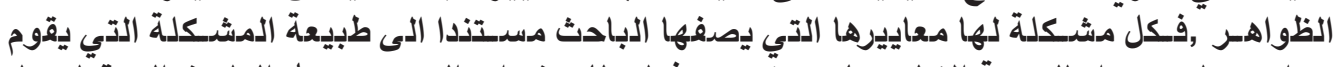

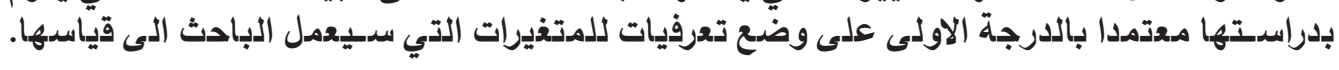

تعريف القياس

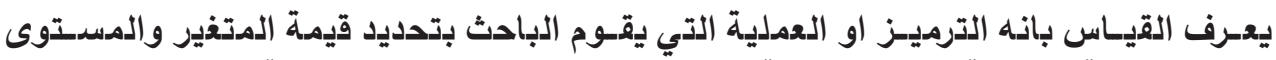

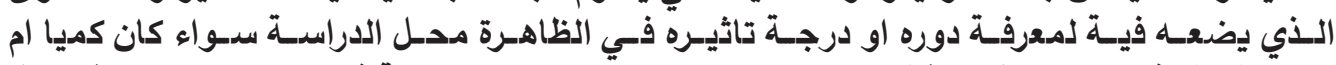

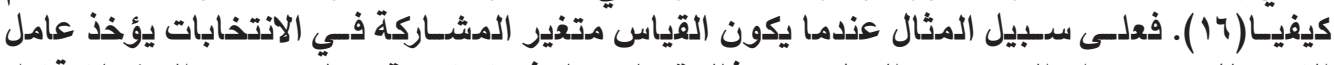

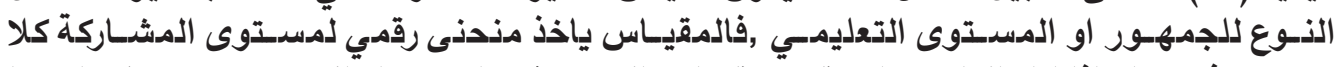

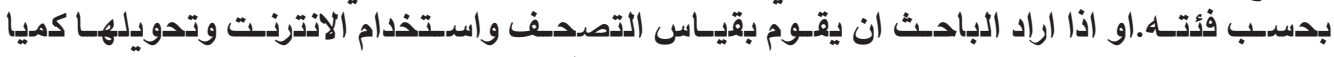

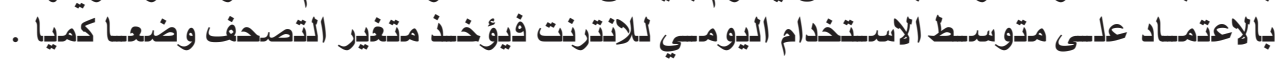

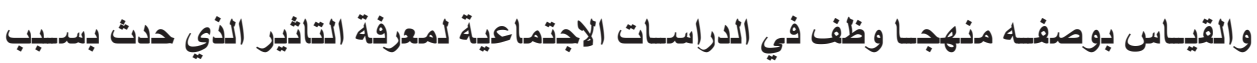

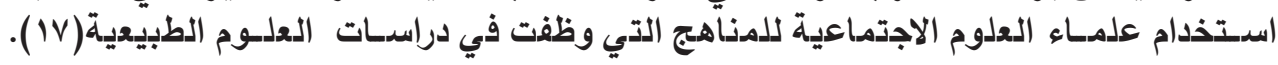


مفهوم القياس

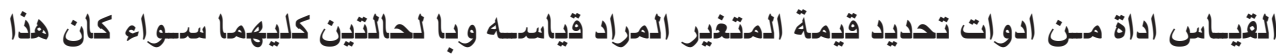

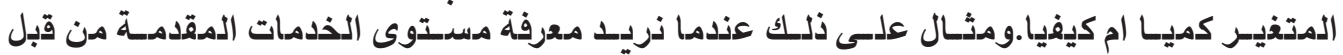

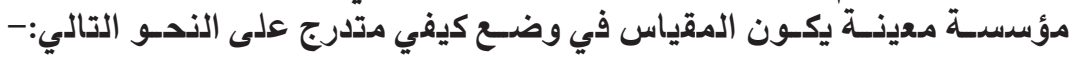

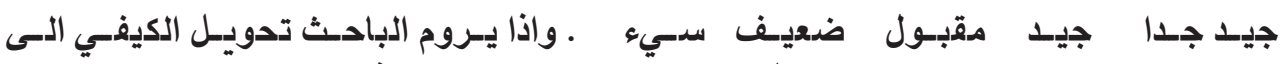

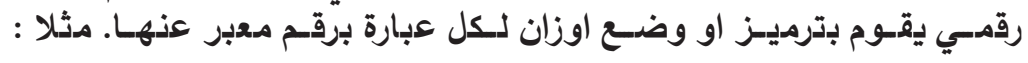

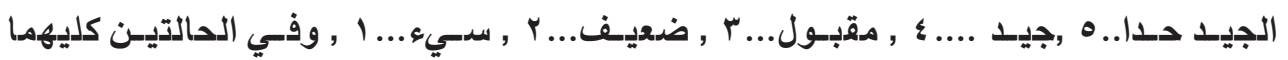

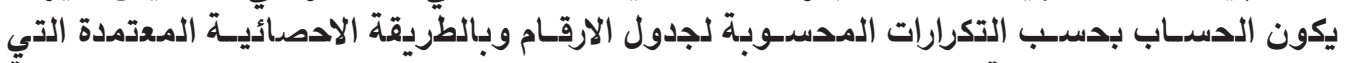

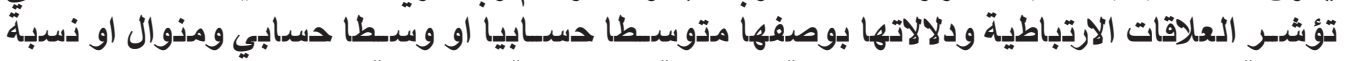

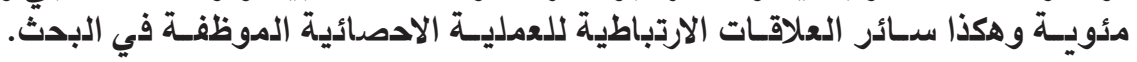

اهمية القياس

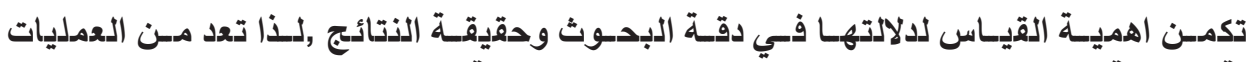

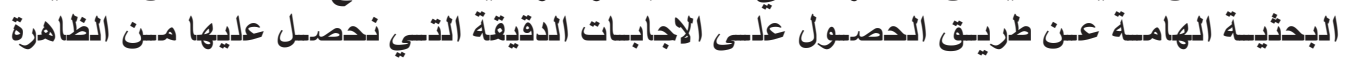
المدروســة .وتعــ اهميـة القيـاس مهمدة للاسدباب الاتيـة:

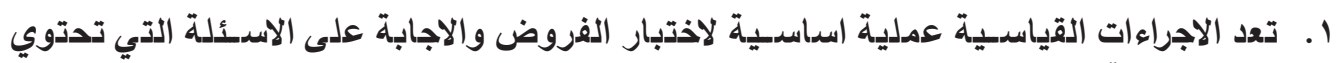

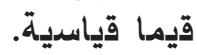

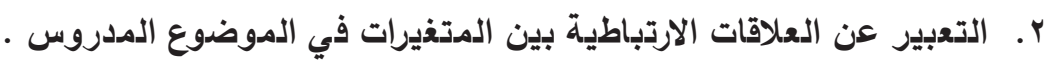

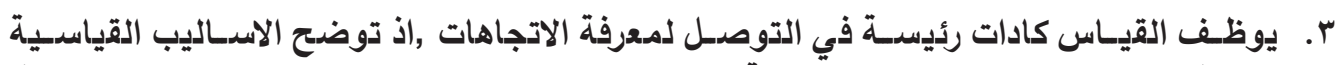

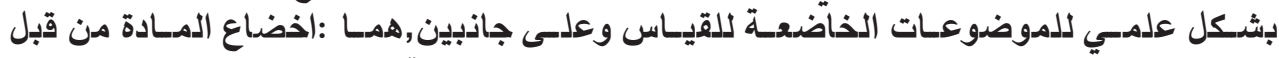

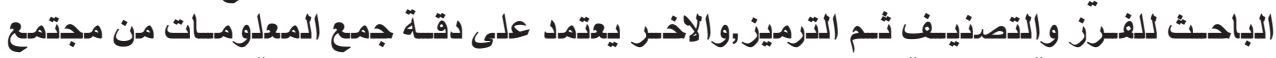

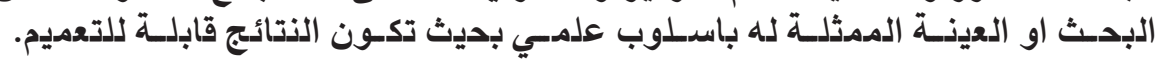

؛. . تميز النتائج التي يتم التوصل اليها بالديادية بعد اخضاعها للدالاتلات الاحصائية.

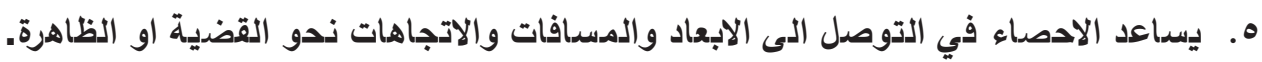

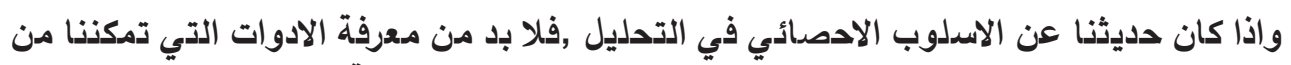

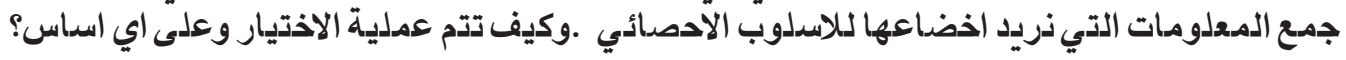

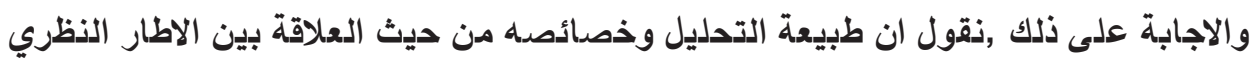

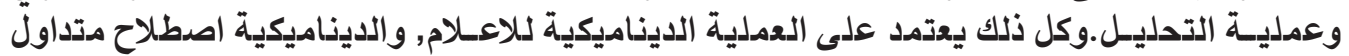

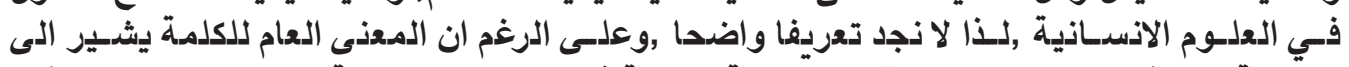

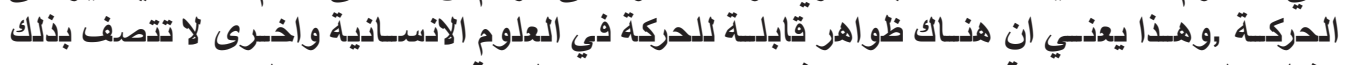

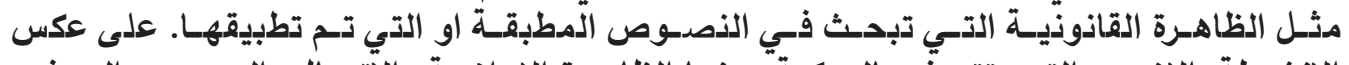

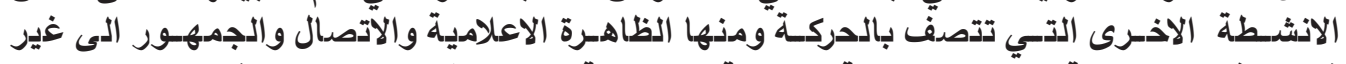

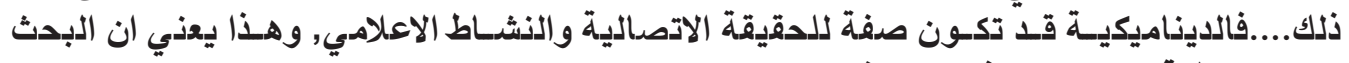

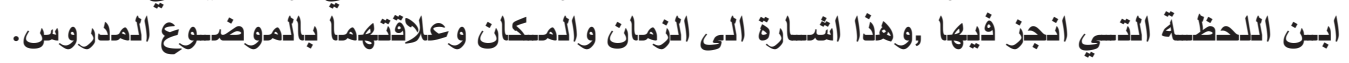




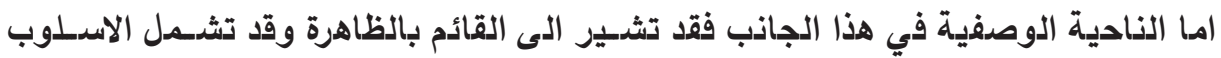

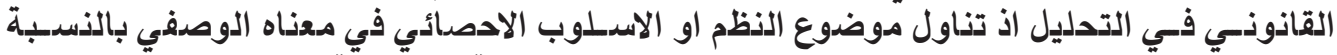

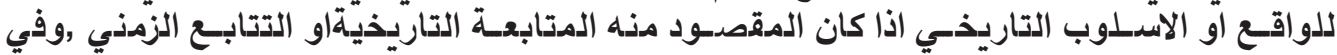

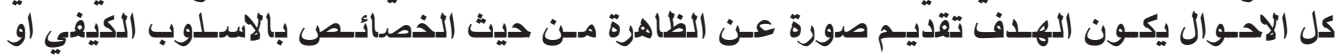

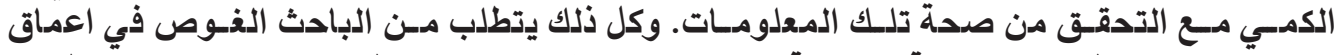

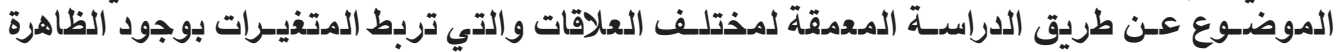

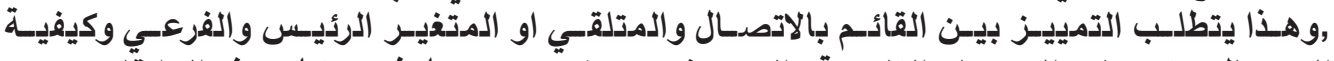

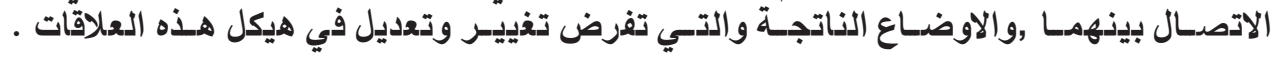

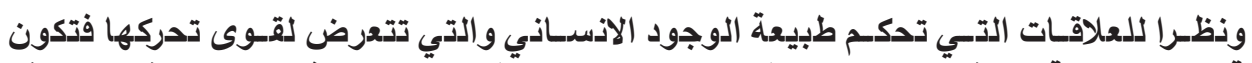

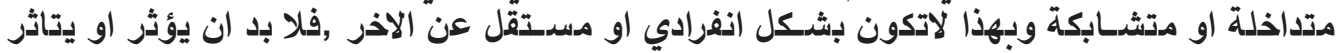

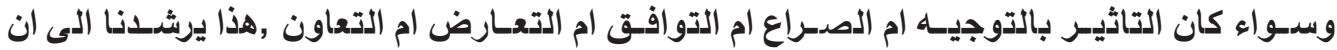

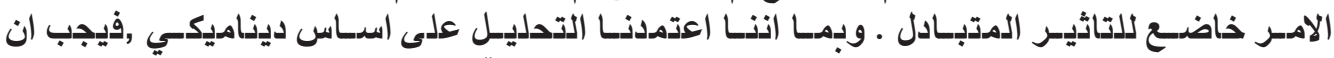

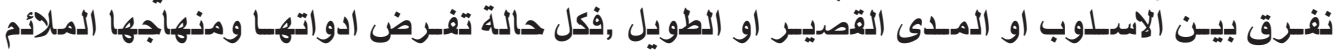

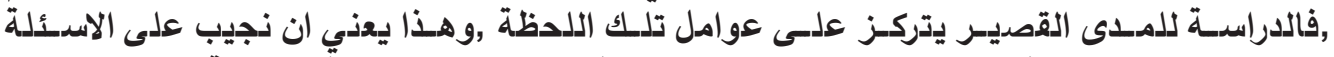

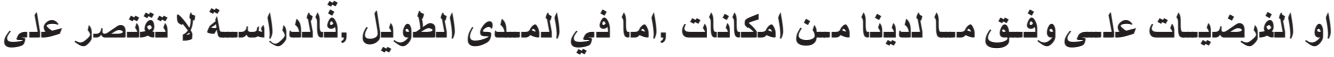

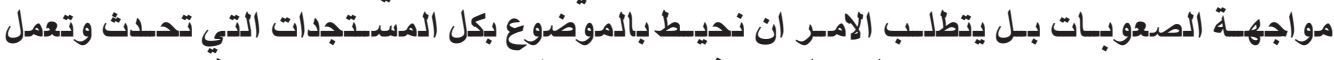

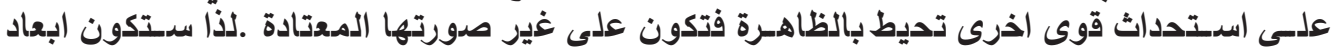

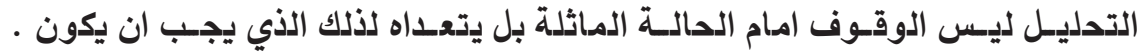

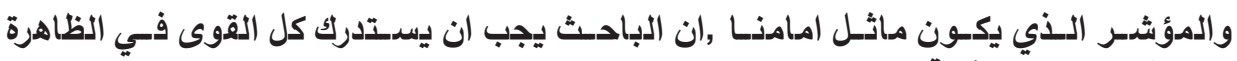

$$
\text { والتـي تحيط بها, والمتثمثلـة بالاتي:- }
$$

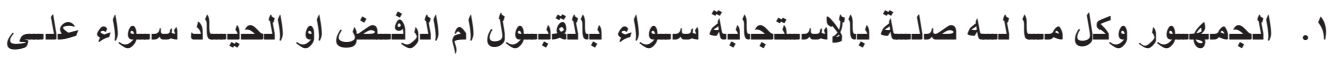

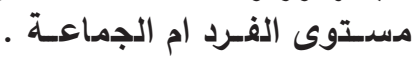

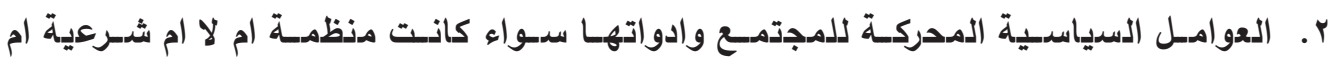

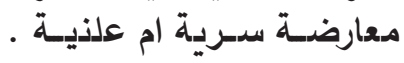

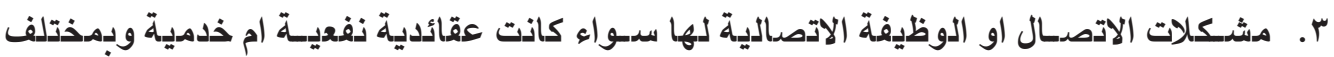

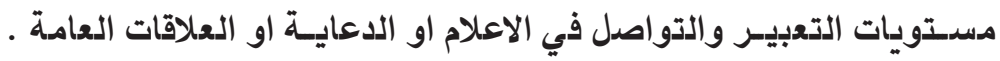

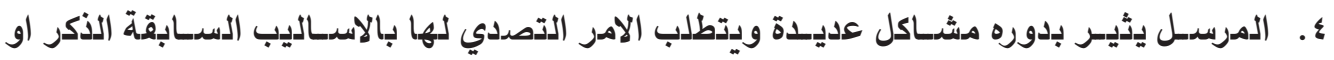
باسدوب جديد.

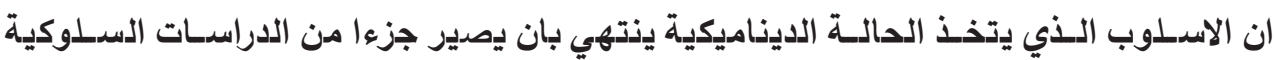

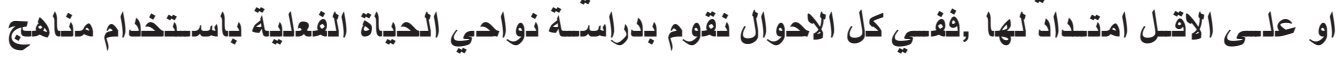

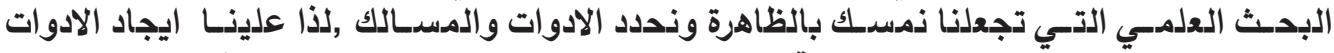

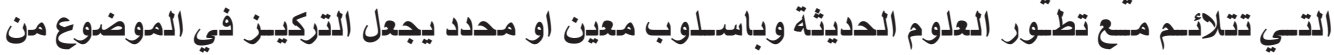

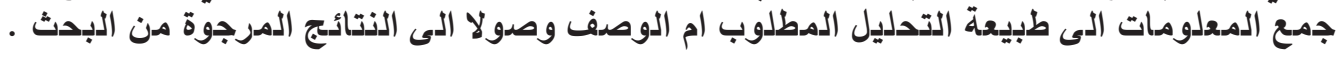

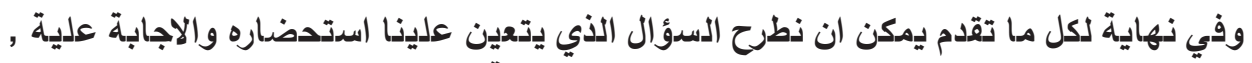

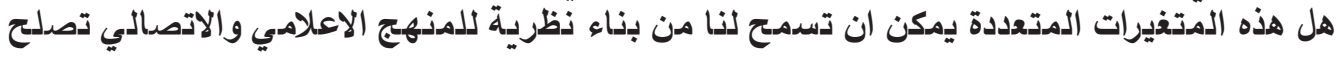




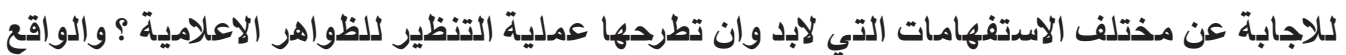

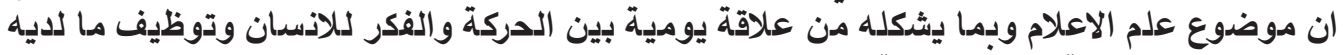

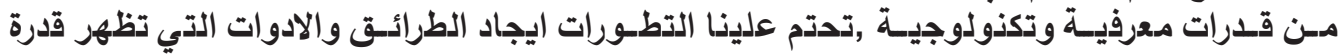

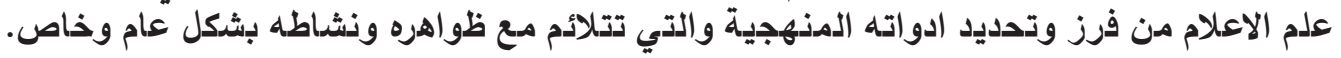

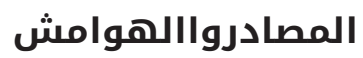

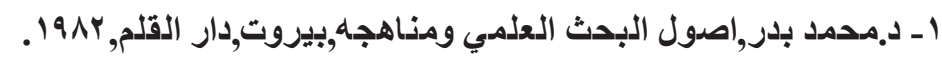

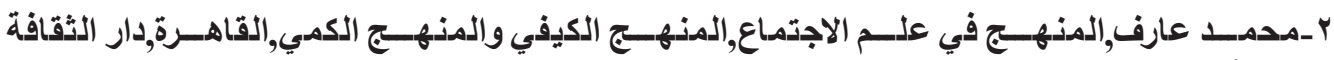
للطباعة والنشـر, 19Vr. .p ${ }^{\mu 99.1979 . S i m o n . ~ J . B a s i c ~ R e s e r c h ~ M e t b o d s ~ i n ~ S o c i a l ~ S i e n c e ~-~} r$

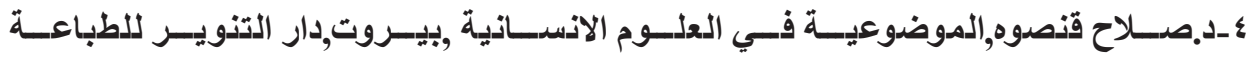

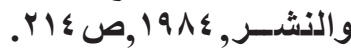

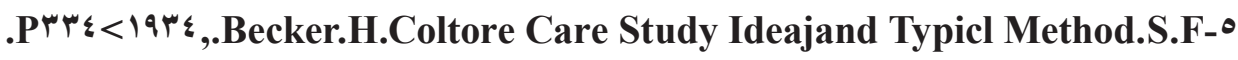
\-محمد فتحي الشنيطي ,اسس المنطق والمنهج العلمي, بيروت,دار النهضة العربية, ،19v.

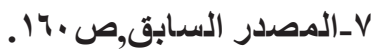

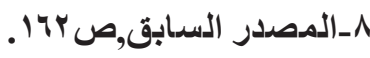

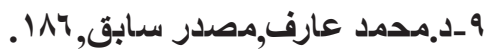

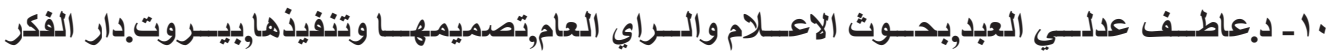

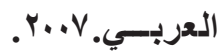

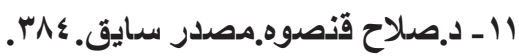

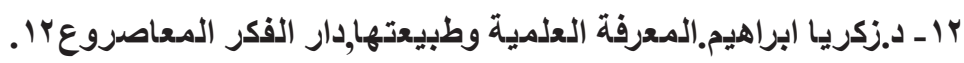

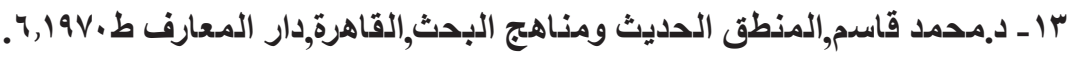

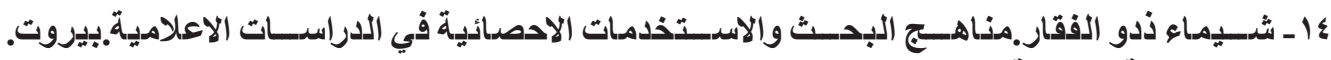

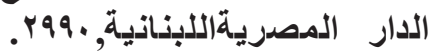

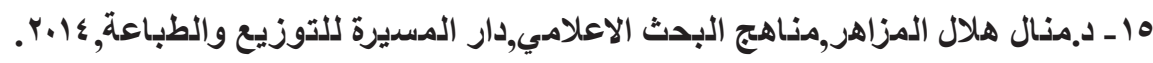

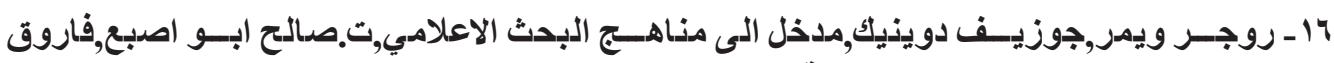
منصور,مركز دراســات الوحدة العربية. با.بr.

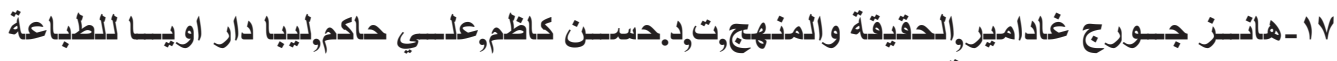

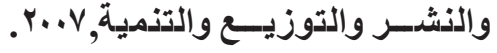




\section{Top of Form}

\section{Almsadr}

1-.muhamad bidra,asul albahth aleilmi wamanahijha,biruta,dar alqlm,1982

2-mihamad earf,almunhj fi eilm alaijtimae,almunhij alkayfi walmunhaj alkamia,alqahirta,dar althaqafat liltabaeat walnashr,1972

3-Simon. J.Basic Reserch Metbods in Social Sience.1969.p399.

4-.silah qunsuha,alimawdaweiat fi aleulum al'iinsaniat, byruta,dar altanwir liltabaeat walnashr,1984,s214.

5-Becker.H.Coltore Care Study Ideajand Typicl Method.S.F.,1934>P334

6 - mihamad fathi alshnyty ,asis almantiq walmanahaj

aleilmi, biruta,dar alnahdat alearabit,1970

7-almasdar alsaabq,s160.

8-almasdar alsaabq,s162

9-.mhamad earfa,msadir sabqa,186

10- .eatif eadaliu aleabda,bihuth al'iielam walraay aleam,tsmimuha watanfidhiha,birut.dar alfikr alerby.2007

11- .slah qunsuhu.msdr sayq.384

12-.zikriaa abrahym.almaerifat aleilmiat watabieatuha,dar alfikr almueasiruea12 .13- .mhmd qasma,almuntiq alhadith wamanahij albahtha,alqahrt,dar almaearif t6.1970.

14- shayma' dhadui alfaqar.manahij albahth walaistukhdimat alahsayiyat fi aldirasat alaielamiti.biruta.aldaar almasritallbnanit,2990

15- .minal hilal almzahr,mnahij albahth alaelami,dar almasirat liltawzie waltabaet,2014.

16- rujr waymira,jawzif duinik,mdkhil 'iilaa manahij albahth alaelamy,t.salih 'abu aisbie,faruq mansur,mirkiz dirasat alwahdat alearabiat.2013

17-hanz jurj ghadamir,alhqayqat walmunhja,t,d.hsn kazma,eli

hakm,liba dar awya liltabaeat walnashr waltawzie waltanmit,2007

Bottom of Form

\begin{tabular}{|c|c|}
\hline & مجلة الباحث الإعلامي \\
\hline$r \leq$ & العدد ( إ ) \\
\hline
\end{tabular}

